\title{
The impact of improved aerosol priors on near-infrared measurements of carbon dioxide
}

\author{
Robert R. Nelson ${ }^{1}$ and Christopher W. O'Dell ${ }^{2}$ \\ ${ }^{1}$ Department of Atmospheric Science, Colorado State University, Fort Collins, CO, USA \\ ${ }^{2}$ Cooperative Institute for Research in the Atmosphere, Colorado State University, Fort Collins, CO, USA
}

Correspondence: Robert R. Nelson (rrnelson@colostate.edu)

Received: 17 October 2018 - Discussion started: 21 November 2018

Revised: 8 February 2019 - Accepted: 18 February 2019 - Published: 7 March 2019

\begin{abstract}
The Orbiting Carbon Observatory-2 (OCO-2) was launched in 2014 with the goal of measuring the columnaveraged dry-air mole fraction of carbon dioxide $\left(X_{\mathrm{CO}_{2}}\right)$ with sufficient precision and accuracy to infer regional carbon sources and sinks. One of the primary sources of error in near-infrared measurements of $X_{\mathrm{CO}_{2}}$ is the scattering effects of cloud and aerosol layers. In this work, we study the impact of ingesting better informed aerosol priors from the Goddard Earth Observing System Model, Version 5 (GEOS-5) into the OCO-2 ACOS V8 retrieval algorithm with the objective of reducing the error in $X_{\mathrm{CO}_{2}}$ from real measurements. Multiple levels of both aerosol setup complexity and uncertainty on the aerosol priors were tested, ranging from a mostly unconstrained aerosol optical depth (AOD) setup to ingesting full aerosol profiles with high confidence. We find that using co-located GEOS-5 aerosol types and AODs with low uncertainty results in a small improvement in the retrieved $X_{\mathrm{CO}_{2}}$ against the Total Carbon Column Observing Network relative to V8. In contrast, attempting to use modeled vertical information in the aerosol prior to improve the $X_{\mathrm{CO}_{2}}$ retrieval generally gives poor results, as aerosol models struggle with the vertical placement of aerosol layers. To assess regional differences in $X_{\mathrm{CO}_{2}}$, we compare our results to a global $\mathrm{CO}_{2}$ model validation suite. We find that the GEOS-5 setup performs better than V8 over northern Africa and central Asia, with the standard deviation of the $X_{\mathrm{CO}_{2}}$ error reduced from 2.12 to $1.83 \mathrm{ppm}$, due to a combination of smaller prior AODs and lower prior uncertainty. In general, the use of better informed aerosol priors shows promise but may be restricted by the current accuracy of aerosol models.
\end{abstract}

\section{Introduction}

Earth's climate is changing and anthropogenic emissions of greenhouse gases (GHGs) are the primary cause (Stocker et al., 2014). In order to quantify how the climate is changing and what might happen in the future, society needs a reliable method of measuring GHGs. These measurements can then be fed into models to make them more accurate. In 1958, the first regular atmospheric measurements of the most important GHG, carbon dioxide $\left(\mathrm{CO}_{2}\right)$, were established by Charles David Keeling at the South Pole and in Hawaii on Mauna Loa. Since then, levels of $\mathrm{CO}_{2}$ have been observed by additional ground measurement stations and, more recently, satellites orbiting the Earth. These $\mathrm{CO}_{2}$ measurements are then used in carbon flux inversion models to infer regional sources and sinks. Only about half of the carbon dioxide emitted from the burning of fossil fuels actually remains in the atmosphere. The other half is absorbed by so-called sinks on Earth's surface. Both the land and ocean are capable of absorbing $\mathrm{CO}_{2}$, but the partitioning between the two surfaces is uncertain, as well as how different land surface types absorb $\mathrm{CO}_{2}$ (Le Quéré et al., 2009). Space-based measurements of $\mathrm{CO}_{2}$ are one of the best methods available to study $\mathrm{CO}_{2}$, its sources and sinks, and how it impacts Earth's climate now and in the future. This is because space-based measurements provide vastly more global coverage than the current network of ground-based measurements and, when ingested into carbon flux inversion models, could help answer carbon cycle questions (Rayner and O'Brien, 2001; Baker et al., 2010; Chevallier et al., 2007, 2009). However, the precision requirements needed to gain information about the carbon cycle compared to only having ground-based measurements is about 1-2 ppm (Miller et al., 2007; Chevallier et al., 2007, 
Baker et al., 2010). The accuracy requirements are even more demanding: a regional bias of only a few tenths of a part per million may be detrimental to carbon flux inversion models (Basu et al., 2013; Chevallier et al., 2014). Because of this, it is important to reduce errors and biases in space-based measurements of $\mathrm{CO}_{2}$.

Currently, there is a small but growing number of satellites in orbit around Earth designed to measure the columnaveraged dry-air mole fraction of $\mathrm{CO}_{2}$, or $X_{\mathrm{CO}_{2}}$, using reflected, near-infrared sunlight. They are the Greenhouse Gases Observing Satellite (GOSAT; Yokota et al., 2009), the Orbiting Carbon Observatory-2 (OCO-2; Crisp et al., 2008), and TanSat (Yang et al., 2018). Thermal infrared instruments, such as the Atmospheric Infrared Sounder (Susskind et al., 2003) and the Infrared Atmospheric Sounding Interferometer (Pougatchev et al., 2009), can measure $\mathrm{CO}_{2}$ in certain parts of the atmosphere but are typically not sensitive near the surface, where the fluctuations in $\mathrm{CO}_{2}$ are greatest. Because of their sensitivity to the full column of $\mathrm{CO}_{2}$, near-infrared measurements currently provide the most valuable information on $\mathrm{CO}_{2}$ in the atmosphere. This work is focused on the $X_{\mathrm{CO}_{2}}$ retrieval algorithm applied to measurements from OCO-2. OCO-2 is in a sun-synchronous orbit in the NASA Afternoon Train (L'Ecuyer and Jiang, 2010) and has eight adjacent footprints that each measure approximately $1.25 \mathrm{~km}$ by $2 \mathrm{~km}$. It takes approximately 1000000 measurements a day, of which on average 100000 are cloud-free.

One of the main sources of error in space-based measurements of $X_{\mathrm{CO}_{2}}$ is the scattering of sunlight by clouds and aerosols. This is because these contaminants can modify the light path seen by the satellite's sensor in ways that are difficult to quantify. Completely neglecting clouds and aerosols in measurements of $X_{\mathrm{CO}_{2}}$ can result in errors that exceed $1 \%$ (around $4 \mathrm{ppm}$ of $\mathrm{CO}_{2}$ ) and can be much larger for scenes containing significant contamination (O'Brien and Rayner, 2002; Aben et al., 2007; Butz et al., 2009). Even when scenes are heavily screened to remove clouds and aerosols, a nonscattering retrieval performs $20 \%-40 \%$ worse than one that includes some way to account for scattering effects (Nelson et al., 2016).

Typically, one or more pieces of information about clouds and aerosols are solved for in addition to $X_{\mathrm{CO}_{2}}$. Some common methods include retrieving various optical properties of an aerosol type (Kuang et al., 2002; Yokota et al., 2009; Butz et al., 2011), retrieving vertical aerosol information (Crisp et al., 2010; Parker et al., 2011; Butz et al., 2011; Reuter et al., 2016), retrieving parameters directly related to the photon path length (Oshchepkov et al., 2008), and parameterizing aerosols with a single isotropic scattering layer (Reuter et al., 2017). All these methods are intended to act as proxies to the real scattering effects of clouds and aerosols in the column in order to allow an accurate $X_{\mathrm{CO}_{2}}$ to be retrieved. However, it is not clear that any one method is best. The current operational OCO-2 $X_{\mathrm{CO}_{2}}$ retrieval algorithm, known as Atmospheric Carbon Observations from Space (ACOS;
O'Dell et al., 2012; Crisp et al., 2010) version 8 (V8; O'Dell et al., 2018), includes nine parameters related to clouds and aerosols, which describe an ice cloud, water cloud, and three aerosol types. However, retrieved aerosol optical depths (AODs) from ACOS generally compare poorly to the highly accurate AErosol RObotic NETwork (AERONET, Holben et al., 1998; Nelson et al., 2016). This indicates that the way ACOS handles the scattering effects of clouds and aerosols can potentially be improved. While the goal of parameterizing these scattering effects is to account for light path modifications and not necessarily to retrieve cloud and aerosol properties, it is hypothesized that any improvements will lead to reduced $X_{\mathrm{CO}_{2}}$ errors.

One choice that impacts how well the retrieved cloud and aerosol parameters perform is the use of prior information to constrain the problem. Often, a constant or climatological value with high uncertainty applied to it is used for the aerosol setup (e.g. Parker et al., 2011; O'Dell et al., 2012). In this work, we test the hypothesis that using more realistic aerosol priors will allow the retrieved aerosol parameters to better represent the scattering of light in the column and thus reduce the error in retrieved $X_{\mathrm{CO}_{2}}$. Specifically, we examine the impact of using co-located modeled aerosols from the Goddard Earth Observing System Model, Version 5 (GEOS-5) as prior information on the retrieved $X_{\mathrm{CO}_{2}}$ from real OCO-2 measurements. Global atmospheric models, such as GEOS-5, are highly sophisticated and contain many layers of complex physics to represent aerosol processes in the atmosphere including aerosol dynamic schemes and size-resolved aerosol microphysics (Mann et al., 2014). However, atmospheric models do not perfectly represent reality. There are still large differences among individual models, which are restricted by uncertainties in aerosol emission source characteristics, knowledge of atmospheric processes, and the meteorological field data used (Dubovik et al., 2008). Despite this, it is hypothesized that these models will still be of use in the $X_{\mathrm{CO}_{2}}$ retrievals. We also examine the uncertainties applied to the aerosol priors in the current OCO-2 $X_{\mathrm{CO}_{2}}$ retrieval algorithm to see if using a lower uncertainty, in conjunction with a more realistic aerosol prior, results in an improvement in $X_{\mathrm{CO}_{2}}$ against multiple validation sources. Finally, we test whether vertical aerosol information from GEOS- 5 can be successfully ingested. These results impact not only OCO-2, but also $X_{\mathrm{CO}_{2}}$ from GOSAT, TanSat, and several other future space-based GHG missions that will also be significantly influenced by the scattering effects of clouds and aerosols.

Section 2 gives an overview of the OCO-2 ACOS $X_{\mathrm{CO}_{2}}$ retrieval algorithm and the prior information it uses. Section 3 discusses the two validation datasets used in this study along with filtering and bias correction. Section 4 describes our use of instantaneous modeled aerosols as prior information in the retrieval while Sect. 5 presents the results. Section 6 summarizes the study's results and determines if the use of more 
realistic modeled aerosols is beneficial in near-infrared retrievals of $X_{\mathrm{CO}_{2}}$.

\section{$2 \quad X_{\mathrm{CO}_{2}}$ retrieval algorithm}

In this section, we will discuss the current OCO-2 retrieval algorithm, ACOS V8, and its cloud and aerosol parameterization. The remote sensing of $\mathrm{CO}_{2}$ using reflected nearinfrared sunlight is typically accomplished by measuring absorption in an oxygen line and one or more $\mathrm{CO}_{2}$ lines. For OCO-2, GOSAT, and TanSat, the $\mathrm{O}_{2}$ A-band at $0.76 \mu \mathrm{m}$ is used in conjunction with a weak $\mathrm{CO}_{2}$ absorption band at $1.6 \mu \mathrm{m}$ and a strong $\mathrm{CO}_{2}$ absorption band at approximately $2.0 \mu \mathrm{m}$. The main purposes of the $\mathrm{O}_{2}$ band are to estimate the path length of the photons detected by the satellite and to filter out clouds and aerosols (by screening for large variations from the expected path length). As there are only 1.5-2.0 pieces of information about the vertical distribution of $\mathrm{CO}_{2}$ from OCO-2 (Connor et al., 2008), the columnaveraged dry-air mole fraction of carbon dioxide $\left(X_{\mathrm{CO}_{2}}\right)$ is reported:

$X_{\mathrm{CO}_{2}}=\frac{\int_{0}^{\infty} N_{\mathrm{CO}_{2}}(z) \mathrm{d} z}{\int_{0}^{\infty} N_{\mathrm{d}}(z) \mathrm{d} z}$,

where $N_{\mathrm{CO}_{2}}(z)$ is the molecular number density of carbon dioxide and $N_{\mathrm{d}}(z)$ is the molecular dry-air number density at altitude $z$. An optimal estimation technique (Rodgers, 2000) is used to retrieve carbon dioxide and several other parameters that the measured radiances are sensitive to. Generally, optimal estimation takes a state vector containing priors with associated uncertainties, solves a cost function iteratively to find its minimum value, and outputs an optimized state vector with posterior uncertainties for each variable. A full description of the state vector and retrieval technique of the latest OCO-2 algorithm (V8) can be found in O'Dell et al. (2018). The state vector contains approximately 60 elements, including 20 vertical levels of $\mathrm{CO}_{2}$, surface pressure, banddependent surface albedo, total column water vapor, a temperature profile offset, several cloud and aerosol parameters, and others. The aerosol setup contains five particle types: a water cloud, ice cloud, two aerosol types from a Modern-Era Retrospective analysis for Research and Applications, Version 2 (MERRA-2; Rienecker et al., 2011) climatology, and a stratospheric aerosol type. This MERRA-2 climatology is simply the monthly means for 1 year for each of the five MERRA-2 aerosol types (dust, organic carbon, black carbon, sea salt, sulfate). The two types chosen to be included in the state vector are the two with the highest climatological mean AOD for a given month and location. For example, if dust and organic carbon are the two largest AODs of the possible five in the month of July for a given location, then they are selected as the two types to be retrieved for any July OCO-2 sounding for that location. The vertical profile of these aerosol types are described by Gaussian distributions.

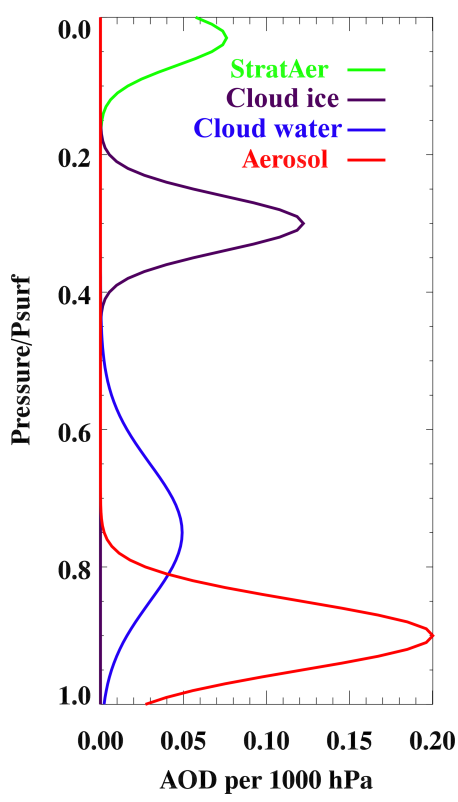

Figure 1. Prior Gaussian profiles of the lower tropospheric aerosol types (red), water cloud (blue), ice cloud (purple), and stratospheric aerosol (green). The local AOD per unit of pressure at $755 \mathrm{~nm}$ is plotted as a function of the relative pressure. The lower tropospheric aerosol prior AOD is not fixed as for the other types, but rather it is taken from a climatology described in the text. Taken from O'Dell et al. (2018).

The height and magnitude (amplitude) of the Gaussian distribution are retrieved for each of the two aerosol types, water cloud, and ice cloud. The magnitude of the stratospheric aerosol type is solved for, but the height is fixed. The widths of the five Gaussian profiles are fixed, as it has been shown that the radiances are not especially sensitive to the width of a cloud or aerosol layer (Butz et al., 2009; Frankenberg et al., 2012). The prior Gaussian profiles are shown in Fig. 1, from O'Dell et al. (2018).

Thus, nine parameters are included in the state vector that directly describe the clouds and aerosols in the scene. Additionally, the natural log of the AOD is the parameter solved for that describes the magnitude of each Gaussian profile. This is to prevent the algorithm from attempting to retrieve a negative AOD, which would result in the retrieval crashing due to current algorithmic limitations. The retrieved height of the Gaussian profile represents the fraction of the surface pressure. For example, if the surface pressure is $1000 \mathrm{hPa}$ and the retrieved height parameter is 0.5 , the Gaussian profile will be centered at $500 \mathrm{hPa}$.

\section{Data}

In this work, we use two datasets to evaluate the quality of the OCO-2 $X_{\mathrm{CO}_{2}}$ retrievals in the context of testing the aerosol parameterization. While we expect the retrieved aerosol pa- 


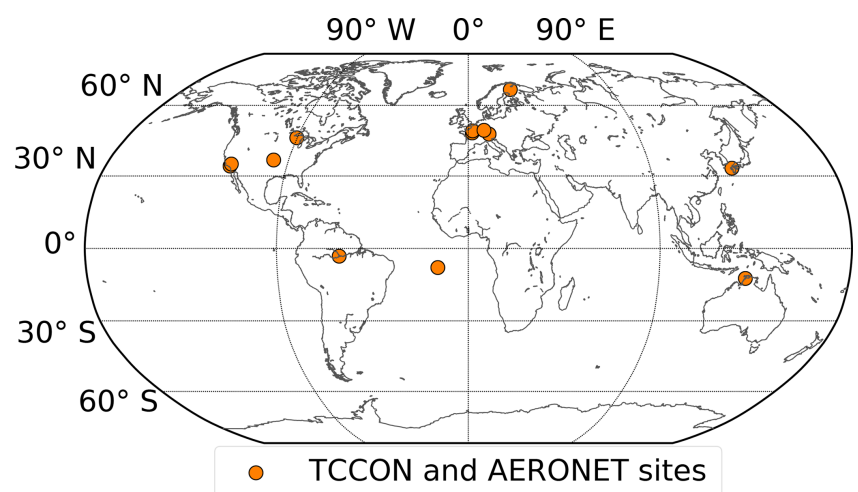

Figure 2. Validation locations used in this study. Every site contained both a TCCON and AERONET station.

rameters to improve with the use of a more accurate prior, the retrieved aerosols are still only designed to be effective scattering parameters and thus we will not evaluate their quality in this work. The first validation dataset is 32175 retrievals co-located with 13 Total Carbon Column Observing Network (TCCON; Wunch et al., 2011) and AERONET sites across the globe. The second is a dataset of 30827 retrievals matched with an ensemble of global $\mathrm{CO}_{2}$ models for which we consider the truth the median of the $\mathrm{CO}_{2}$ models in places where they agree to within $1 \mathrm{ppm}$. These two validation sets complement each other in that TCCON is known to be highly accurate but with limited spatial coverage. The model validation dataset likely has larger uncertainty than TCCON but provides excellent spatial coverage.

\subsection{TCCON-AERONET validation dataset}

The TCCON validation dataset contained 32175 OCO-2 measurements taken from 17 September 2014 to 2 May 2016. We co-located the OCO-2 measurements in time and space with AERONET and TCCON, which were required to be both present and operational at a given site. The co-location criteria were within $1^{\circ}$ latitude-longitude and $\pm 30 \mathrm{~min}$ and the sites selected for use are shown in Fig. 2. As TCCON stations are all located on land, only a small fraction of colocated soundings are over water surfaces.

Table 1 lists the TCCON sites used in this study. The soundings were selected from a set of OCO-2 "lite" files (Osterman et al., 2017) that had been pre-filtered (see Sect. 3.3). We then post-processed the retrievals with multiple custom filters in an attempt to remove all scenes contaminated by clouds or aerosols.

\subsection{Model validation dataset}

In addition to validation against the highly accurate but sparsely located TCCON, a set of global $\mathrm{CO}_{2}$ models was assembled in order to examine spatial errors. We co-located 30827 OCO-2 soundings in time and space with a suite of nine global carbon models (Peters et al., 2007; Feng et al., 2011; Baker et al., 2010; Liu et al., 2017; Crowell et al., 2018; Rödenbeck, 2005; Inness et al., 2013; Basu et al., 2013; Schuh et al., 2019). Only points where all the models agreed to within $1 \mathrm{ppm}$ of $X_{\mathrm{CO}_{2}}$ were used. Work by O'Dell et al. (2018) has shown that using this methodology produces similar error statistics to that of the TCCON validation. The median $X_{\mathrm{CO}_{2}}$ of the nine models for each of the 30827 soundings was used as the truth metric. The OCO2 soundings were selected by sorting all the measurements into a $4^{\circ} \times 4^{\circ}$ spatial grid and filling all grid boxes with up to 10 soundings. This allowed for excellent global coverage while limiting the demand on the available computational resources needed to run the retrievals.

\subsection{Filtering and bias correction}

As OCO-2 struggles with scenes containing clouds and aerosols, multiple strategies are used to try and filter out any scene that is contaminated by scattering particles. For both validation datasets, the $\mathrm{O}_{2}$ A-band Preprocessor (ABP; Taylor et al., 2016) and iterative maximum a posteriori differential optical absorption spectroscopy (IMAP-DOAS) preprocessor (IDP; Frankenberg et al., 2005) were applied to every measurement before being selected to run through the retrieval. For each validation set, the approximately 30000 soundings used in this study were those that had successfully passed through the preprocessors. These soundings were determined to be clear enough to be run through the retrieval. After removing soundings that failed to converge, post-processing filtering techniques were applied to remove additional low-quality retrievals that were not screened out by the preprocessors. These filters included the reduced $\chi^{2}$ (for which $\chi^{2}$ in all three bands must be less than 2.0), a delta pressure parameter (" $\mathrm{dp} \mathrm{p}_{\mathrm{abp}}$ " from $\mathrm{ABP}$, where $\mathrm{dp}$ abp $<$ $750 \mathrm{hPa}$ ), and the $\mathrm{CO}_{2}$ and $\mathrm{H}_{2} \mathrm{O}$ ratios (from IDP, where $1.00<\mathrm{CO}_{2}$ ratio $<1.02$ and $0.88<\mathrm{H}_{2} \mathrm{O}$ ratio $<1.01$ ). After applying these filters, the remaining OCO-2 measurements had co-located AERONET AODs of less than 0.25 and thus all tests are being carried out on a mostly clear-sky dataset and conclusions cannot be drawn about how these retrieval modifications impact the results if scenes with thick cloud or aerosol layers are present. Additionally, as the TCCON stations are located on land, the final post-filtered validation dataset only contained land measurements and thus no conclusions can be made about OCO-2 measurements over ocean for the TCCON validation study.

Despite heavy pre- and post-filtering of the dataset to remove cloud and aerosol layers, no atmospheric column is truly free from scattering particles. Thus, a bias correction is typically applied to the final $X_{\mathrm{CO}_{2}}$ in an attempt to mitigate retrieval errors caused by remaining scattering effects and other sources of error including imperfect spectroscopy (O'Dell et al., 2018). In the operational V8 product, considerable effort is put into developing a multiparameter bias cor- 
Table 1. TCCON stations used in this study.

\begin{tabular}{lll}
\hline TCCON station & Dates used & Reference \\
\hline Ascension Island & Sep 2014-Dec 2015 & Feist et al. (2014) \\
Caltech, Pasadena, CA, USA & Sep 2014-May 2016 & Wennberg et al. (2015) \\
Darwin, Australia & Sep 2014-May 2016 & Griffith et al. (2014) \\
Edwards (Armstrong), CA, USA & Sep 2014-Mar 2016 & Iraci et al. (2016) \\
Garmisch, Germany & Sep 2014-Nov 2015 & Sussmann and Rettinger (2014) \\
Karlsruhe, Germany & Sep 2014-May 2016 & Hase et al. (2015) \\
Lamont, OK, USA & Sep 2014-May 2016 & Wennberg et al. (2016) \\
Manaus, Brazil & Oct 2014-Jun 2016 & Dubey et al. (2014) \\
Orléans, France & Sep 2014-Nov 2015 & Warneke et al. (2014) \\
Paris, France & Sep 2014-Sep 2015 & Te et al. (2014) \\
Park Falls, WI, USA & Sep 2014-May 2016 & Wennberg et al. (2014) \\
Saga, Japan & Sep 2014-Feb 2016 & Kawakami et al. (2014) \\
Sodankylä, Finland & Sep 2014-Apr 2016 & Kivi and Heikkinen (2016) \\
\hline
\end{tabular}

rection that reduces the $X_{\mathrm{CO}_{2}}$ bias against several independent truth metrics. In this work, a single-parameter bias correction was selected for each validation dataset for simplicity and to ensure a fair comparison across different setups. The parameter chosen was that which had the largest correlation with $X_{\mathrm{CO}_{2}}$ error. When comparing to TCCON, the retrieved $X_{\mathrm{CO}_{2}}$ was bias corrected by removing a linear fit between the $X_{\mathrm{CO}_{2}}$ error (retrieved $X_{\mathrm{CO}_{2}}-$ TCCON $X_{\mathrm{CO}_{2}}$ ) and the difference between the retrieved surface pressure and the prior surface pressure ("dp"). This was the most correlated parameter in the majority of our TCCON tests and thus was selected as the bias correction parameter. This parameter is correlated with $X_{\mathrm{CO}_{2}}$ biases because any unparameterized clouds and aerosols in the column can make the retrieval think there is a lower surface pressure than in reality. Thus, bias correcting this mistake is designed to bring the retrieved surface pressures back to realistic values and can approximately account for the improperly parameterized clouds and aerosols. In the case of the model validation dataset, the bias correction parameter was the solar zenith angle. Physically, this represents the removal of artificial biases induced by longer air masses. The reason why this parameter was selected over $\mathrm{dp}$ is that the model dataset has excellent latitudinal coverage and thus the air mass is weighted more than dp. TCCON, however, is spatially limited and, despite seasonal variations in sun angle, the air mass dependence is not as prevalent when searching for optimal bias correction parameters.

\section{Modeled aerosol priors}

As discussed in Sect. 2, the OCO-2 retrieval algorithm has several aerosol parameters in its state vector. The prior values for most of these parameters in V8 are fixed or taken from a monthly climatology. Here, we discuss several methods in which we test the use of instantaneous 3-D modeled aerosol data as prior information to improve upon the current priors with the hope of increasing the precision and accuracy of the final OCO-2 $X_{\mathrm{CO}_{2}}$ product.

The GEOS-5 Forward Processing for Instrument Teams (GEOS-5 FP-IT; Rienecker et al., 2008) weather forecasting model, created and maintained by the NASA Global Modeling and Assimilation Office, is designed specifically for instrument teams in that the entire period (2000-current) is run using the same GEOS-5 version to maintain consistency and avoid any unwanted biases from updates to the model. For this work, GEOS-5 FP-IT version 5.12.4, hereafter referred to as GEOS-5, was co-located in time and space with the OCO-2 soundings. GEOS-5 is on a $0.625^{\circ}$ longitude by $0.5^{\circ}$ latitude horizontal grid with 72 vertical layers extending to $0.01 \mathrm{hPa}$ with a time step of $3 \mathrm{~h}$. The model was linearly interpolated in space and the nearest $3 \mathrm{~h}$ model update was chosen in time. For example, if the OCO-2 sounding was taken at 19:00 UTC, the 18:00 UTC model run was used. The GEOS-5 aerosol scheme contains 15 different types with up to five different size bins for each type, which we aggregate into five unique types: dust, organic carbon, black carbon, sea salt, and sulfate. The aggregation process weights by the typical relative amount of optical depth contributed by each type at $760 \mathrm{~nm}$ and uses a typical relative humidity value for the hygroscopic types. Each type has unique optical properties, including the single-scattering albedo, extinction coefficient, and refractive index. Further details can be found in Crisp et al. (2010). GEOS-5 ingests Terra Moderate Resolution Imaging Spectroradiometer (MODIS; Kaufman et al., 1997) AOD, Aqua MODIS AOD, and Multi-angle Imaging SpectroRadiometer (MISR; Martonchik et al., 1998) aerosol information. AERONET measurements are not used for this product as the data latency is unacceptably large. Figure 3 shows that GEOS-5 AODs correlate better with AERONET compared to both the climatological MERRA-2 AODs and the corresponding retrieved AOD values from OCO-2 V8. Thus, using the model and assigning it some confidence 
should result in an improved correlation in retrieved OCO2 AODs compared to AERONET.

Our primary hypothesis in this work is that using instantaneous modeled aerosol data as prior information will result in smaller $X_{\mathrm{CO}_{2}}$ errors when compared to the current operational setup that uses a monthly climatology. Figure 4 shows the first of the two aerosol types selected when using the MERRA-2 monthly climatology and when using the interpolated GEOS-5 model field. Certain features, such as Saharan dust and biomass burning, are generally realistically placed in the climatology but the day-to-day variations of the atmosphere are not present and thus the climatology is not representative of the true state of the atmosphere for a given OCO-2 sounding location. For example, dust is selected over large portions of the high northern latitudes in the GEOS-5 model field but rarely in the MERRA-2 monthly climatology.

Three methods of varying complexity were chosen to ingest the instantaneous model data:

- using the top two aerosol types and their corresponding AODs;

- using the top two aerosol types and fitting the amplitude, mean, and variance of a Gaussian distribution to the modeled vertical profile of both types;

- using the top two aerosol types and solving for a scale factor on an interpolated 20-layer modeled aerosol profile.

The methodology for selecting which two (of the five) aerosol types to be included in the state vector is simply sorting them by AOD at $760 \mathrm{~nm}$ and selecting the two largest values. The ice cloud, water cloud, and stratospheric aerosol type were always retrieved. The ice cloud and water cloud characteristics were kept the same as V8, while the stratospheric aerosol's optical depth prior and corresponding uncertainty were determined by our setups described below.

\subsection{Types and optical depths}

The first method simply takes the top two aerosol types based on sorting by each type's AOD and uses their corresponding AODs as prior information for each type. This method is the simplest of our tests and does not rely on any modeled vertical aerosol information.

\subsection{Types and Gaussian fits}

The second method takes the largest two aerosol types, as before. The 72-layer GEOS-5 aerosol profiles for both types are then interpolated onto the 20-layer OCO-2 vertical grid. The amplitude, mean, and variance of a Gaussian curve are then fit to that 20-layer profile, and the amplitude (optical depth), height, and width of that Gaussian curve are fed in to the retrieval as prior information. An example is shown in Fig. 5. Occasionally, the fit is a poor representation of the vertical profile. This is often the case with the sulfate type, which can have both a lower tropospheric peak and a stratospheric peak, resulting in a profile that cannot be represented with a single Gaussian profile. To avoid this issue, the sulfate type, if selected, was fit to below $400 \mathrm{hPa}$ and the stratospheric aerosol type (discussed in Sect. 2) was a separate Gaussian fit for the profile above $400 \mathrm{hPa}$. This method was chosen to test the hypothesis that ingesting vertical information from the model will lead to an improved parameterization of the scattering and, subsequently, a more accurate $X_{\mathrm{CO}_{2}}$.

\subsection{Types and scale factors}

The third and most complex method takes the largest two aerosol types sorted by AOD, as before. The 72-layer GEOS5 aerosol profiles for both types are then interpolated onto the 20-layer OCO-2 vertical grid. A scale factor applied to the interpolated profile is then solved for by the retrieval. Because the ACOS retrieval solves for the natural log of the AOD, we solve for an additive scalar which acts as a multiplicative scaling factor when converted to AOD. This means that if the retrieval determines that the scale factor should be 1.5, the GEOS-5 AOD profile magnitude will be multiplied by 1.5. This method is similar to that of Parker et al. (2011), except here we are using a vertical aerosol profile co-located in time and space as the prior, while they use a constant aerosol profile. This method was chosen to test the hypothesis that Gaussian fits are insufficient to realistically parameterize the shapes of true vertical aerosol profiles in the $X_{\mathrm{CO}_{2}}$ retrieval.

\subsection{Aerosol prior uncertainties}

In addition to these three techniques used to modify the aerosol priors, the prior uncertainty must also be considered when using optimal estimation. In the operational ACOS $X_{\mathrm{CO}_{2}}$ retrieval algorithm, the uncertainty on the aerosol parameters is typically very high. For example, a prior AOD of 0.1 is approximately -2.3 in ln-space. Assigning the V8 uncertainty of 2.0 to $\ln (\tau)$ gives $1 \sigma$ values of -4.3 and -0.3 in $\ln$-space, which equates to about 0.014 and 0.74 in optical depth. This large prior uncertainty is due to the lack of confidence in the monthly climatological priors and because it is believed that the radiances themselves should provide enough information to properly constrain the results. However, using this new instantaneous setup allows us to decrease the prior uncertainty because we have more confidence in the GEOS-5 model compared to the monthly climatology, as demonstrated by Fig. 3. The three setups chosen to test are using the operational uncertainty ("high uncertainty"), $25 \%$ of the operational uncertainty ("low uncertainty"), and fixing the prior aerosol values ("no uncertainty"). For example, using our first method above (Sect. 4.1) with low uncertainty means solving for the AODs of the two selected aerosol types with $25 \%$ of the operational uncertainty assigned to the prior values. This means that instead of a $1 \sigma$ uncertainty of 2.0 on 


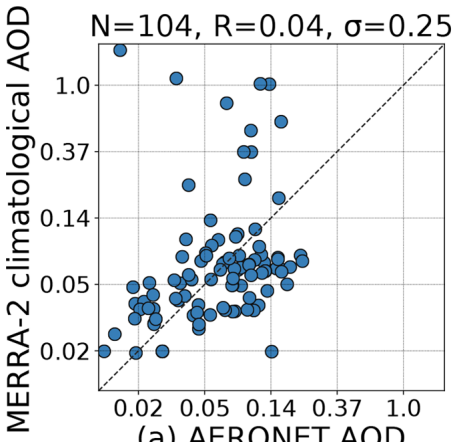

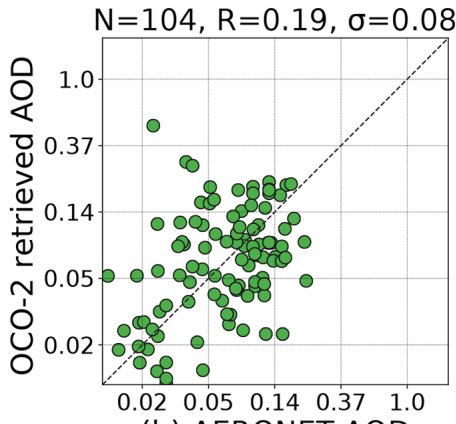

(b) AERONET AOD

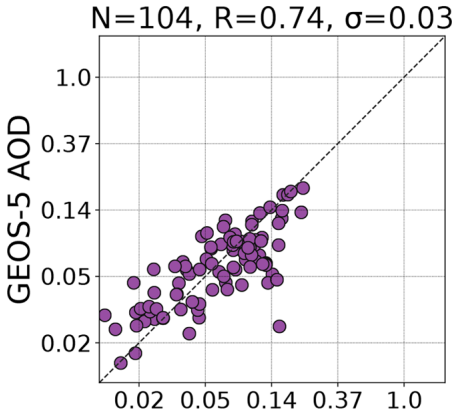

(c) AERONET AOD

Figure 3. (a) MERRA-2 climatological AOD vs. AERONET AOD. (b) OCO-2 V8 retrieved AOD vs. AERONET AOD. (c) GEOS-5 colocated AOD vs. AERONET AOD. The AERONET AODs are the means of the AODs at 675 and $870 \mathrm{~nm}$. Overpass means are plotted. AERONET stations used were those present at the TCCON sites selected for this study, listed in Table 1 and shown in Fig. 2, that had valid data between 17 September 2014 and 2 May 2016.
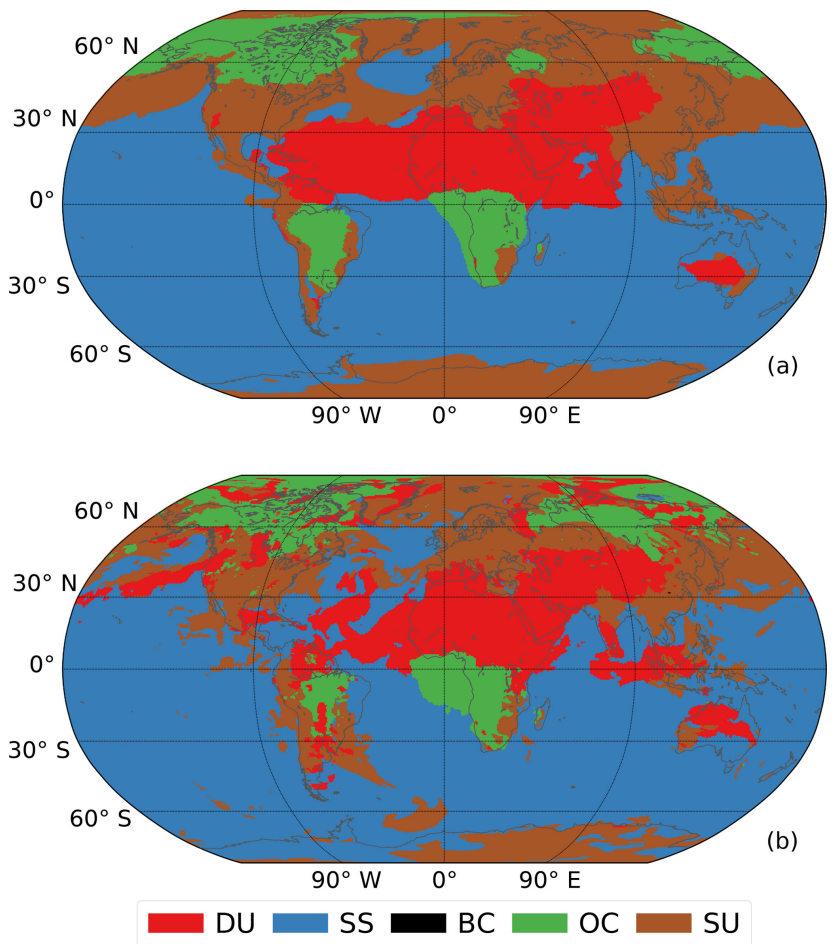

Figure 4. (a) Primary aerosol type selected for the month of July using the MERRA-2 climatology. (b) Primary GEOS-5 aerosol type selected for 1 July 2016 00:00 UTC. Aerosol types are dust (DU), sea salt (SS), black carbon (BC), organic carbon (OC), and sulfate (SU).

$\ln (\tau)$, we assign a value of 0.5 . This equates to a $1 \sigma$ uncertainty range of between 0.06 and 0.16 on a prior AOD of 0.1 . Table 2 lists all the test setups and the corresponding uncertainties on the retrieved $\ln (\tau)$ and, except for the scalar profile tests, the retrieved height. The third method, solving for a 20-layer profile (Sect. 4.3), does not lend itself to assigning single values of uncertainty equivalent to the other two setups. Thus, we assigned layer uncertainties of $\ln (10), 0.5$, and 0.001 for each layer to represent the operational, low, and fixed setups. We also ran the operational retrieval with low and no uncertainty on the AODs in an attempt to isolate the impact of only modifying the prior uncertainties. When ingesting vertical information in the second and third methods, we also reduced the uncertainty of the retrieved height. The width was effectively never retrieved, as it was always assigned an uncertainty of 0.001 .

After processing all 12 retrieval variants, applying similar post-filtering, and matching soundings to ensure a fair comparison, 19471 soundings remained in the TCCON validation dataset while 17355 soundings remained in the model validation dataset. For both datasets and all tests, there were no significant outliers when it came to the percentage of soundings that converged or remained after postfiltering. Typically, the retrievals with very uncertain priors had slightly more soundings fail to converge and the more complex retrieval schemes lost more soundings in postfiltering, but only by a few hundred soundings.

\section{Results}

In this section we discuss the impact of using better informed aerosol priors in the OCO- $2 X_{\mathrm{CO}_{2}}$ retrieval by comparing our test setups to both TCCON and an ensemble of global $X_{\mathrm{CO}_{2}}$ models.

\subsection{TCCON validation results}

Figure 6 shows the results of our test setups alongside the operational retrieval variants (top row). Here, we can see the impact that different prior information and different prior uncertainties have on the retrieved $X_{\mathrm{CO}_{2}}$ when compared to TCCON.

For our nine GEOS-5 test setups, when examining the standard deviation of the error $(\sigma)$, correlation coefficient 

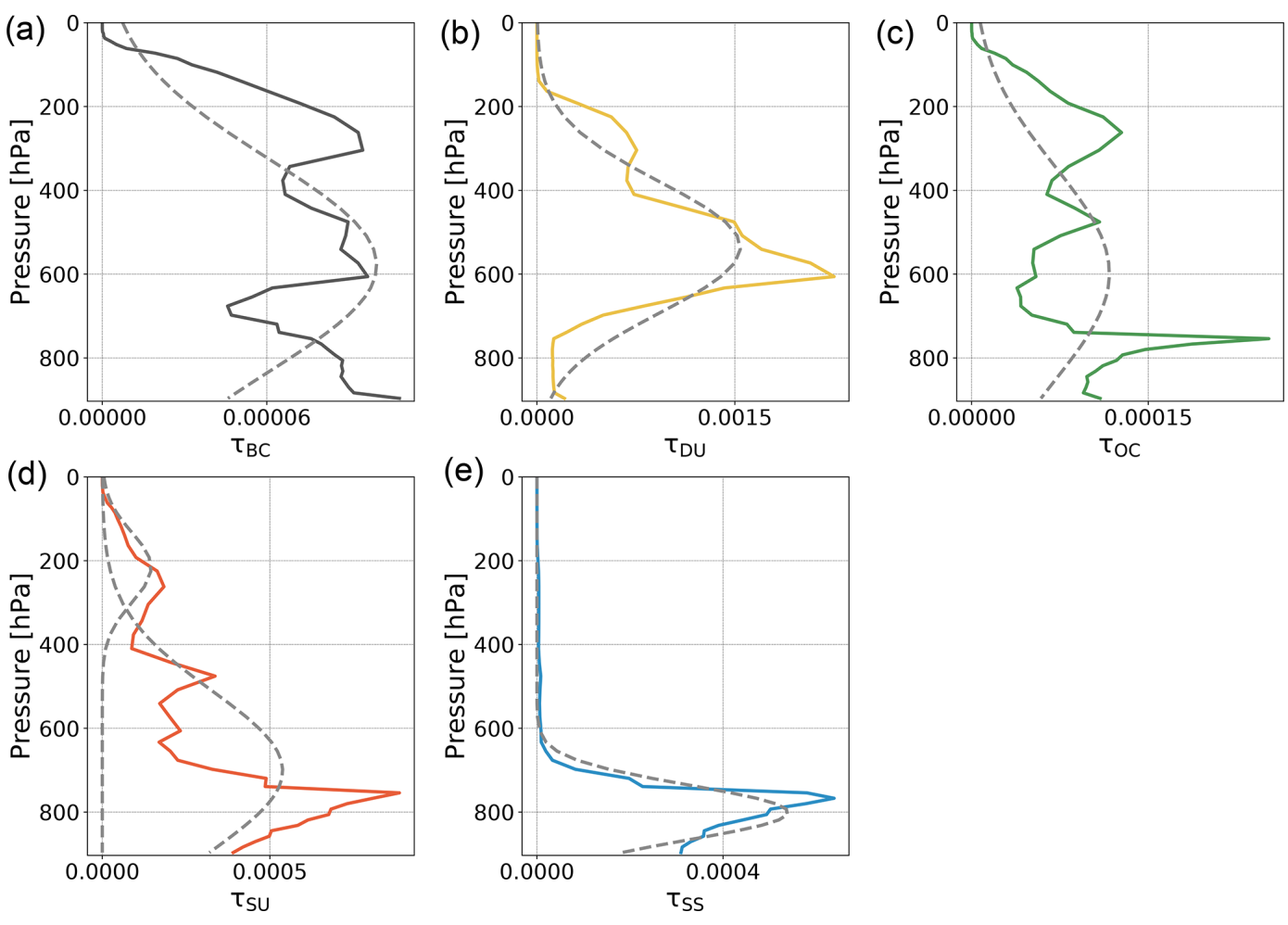

Figure 5. Example of fitting Gaussian distributions to the GEOS-5 AOD profiles. Panel (a) is black carbon, panel (b) is dust, panel (c) is organic carbon, panel (d) is sulfate, and panel (e) is sea salt. Dashed grey lines are the Gaussian fits to the profiles.

Table 2. Prior uncertainties of retrieved natural log of the optical depth, $\sigma_{\tau}$, and retrieved Gaussian heights, $\sigma_{\mathrm{H}}$, for all retrieval variants. The first entry (V8 + MERRA-2 climatological types and AODs with high uncertainty) is equivalent to the operational ACOS retrieval uncertainties. The prior $1 \sigma$ uncertainties on the natural $\log$ of the stratospheric AOD are slightly lower, at $1.8,0.45$, and 0.001 for the three uncertainty levels, respectively.

\begin{tabular}{llll}
\hline Retrieval type & High uncertainty & Low uncertainty & No uncertainty \\
\hline V8 + MERRA-2 climatological types and AODs & $\sigma_{\tau}=2.0, \sigma_{\mathrm{H}}=0.2$ & $\sigma_{\tau}=0.5, \sigma_{\mathrm{H}}=0.2$ & $\sigma_{\tau}=0.001, \sigma_{\mathrm{H}}=0.2$ \\
V8 + GEOS-5 types and AODs & $\sigma_{\tau}=2.0, \sigma_{\mathrm{H}}=0.2$ & $\sigma_{\tau}=0.5, \sigma_{\mathrm{H}}=0.2$ & $\sigma_{\tau}=0.001, \sigma_{\mathrm{H}}=0.2$ \\
V8 + GEOS-5 types and Gaussian profiles & $\sigma_{\tau}=2.0, \sigma_{\mathrm{H}}=0.2$ & $\sigma_{\tau}=0.5, \sigma_{\mathrm{H}}=0.05$ & $\sigma_{\tau}=0.001, \sigma_{\mathrm{H}}=0.0001$ \\
V8 + GEOS-5 types and scalar profiles & $\sigma_{\tau, \text { layer }}=\ln 10$ & $\sigma_{\tau, \text { layer }}=0.5$ & $\sigma_{\tau, \text { layer }}=0.01$ \\
\hline
\end{tabular}

$(R)$, and mean absolute error (MAE) versus TCCON, the values are typically best for the setups in which only the types and the AODs are ingested (second row). When we apply a Gaussian fit to the modeled profiles and use those heights and widths as priors (third row), we see an increase in the scatter against our validation source along with a worse MAE and $R$. Finally, when we solve for a scalar on the modeled aerosol profile (bottom row), we see the largest scatter in $X_{\mathrm{CO}_{2}}$ against TCCON, worst correlations, and highest MAEs. It therefore appears that trying to incorporate vertical information from the aerosol model leads to a worse $X_{\mathrm{CO}_{2}}$.

The only GEOS-5 test setup with errors and a correlation coefficient better than the operational retrieval is the middle panel of the second row (green triangles), in which the types and AODs were ingested with low uncertainty. This may in- dicate that it is reasonable to assign some confidence in the modeled AODs from GEOS-5, rather than leaving it mostly unconstrained. The operational retrieval with low uncertainty (blue triangles) does relatively well but slightly worse than the original V8 (blue squares).

For all retrieval setups, fixing the aerosol input (right column) results in worse error statistics. This is likely because models are not perfect and by entirely removing the retrieval's ability to fit for aerosol effects on the radiances it results in large errors in $X_{\mathrm{CO}_{2}}$. Keeping the prior aerosol uncertainty the same as the operational retrieval (left column), however, appears to allow too much freedom and the aerosol parameters revert to the operational values, regardless of what the prior values are. This is because we are assigning almost no confidence to the prior, so all the informa- 

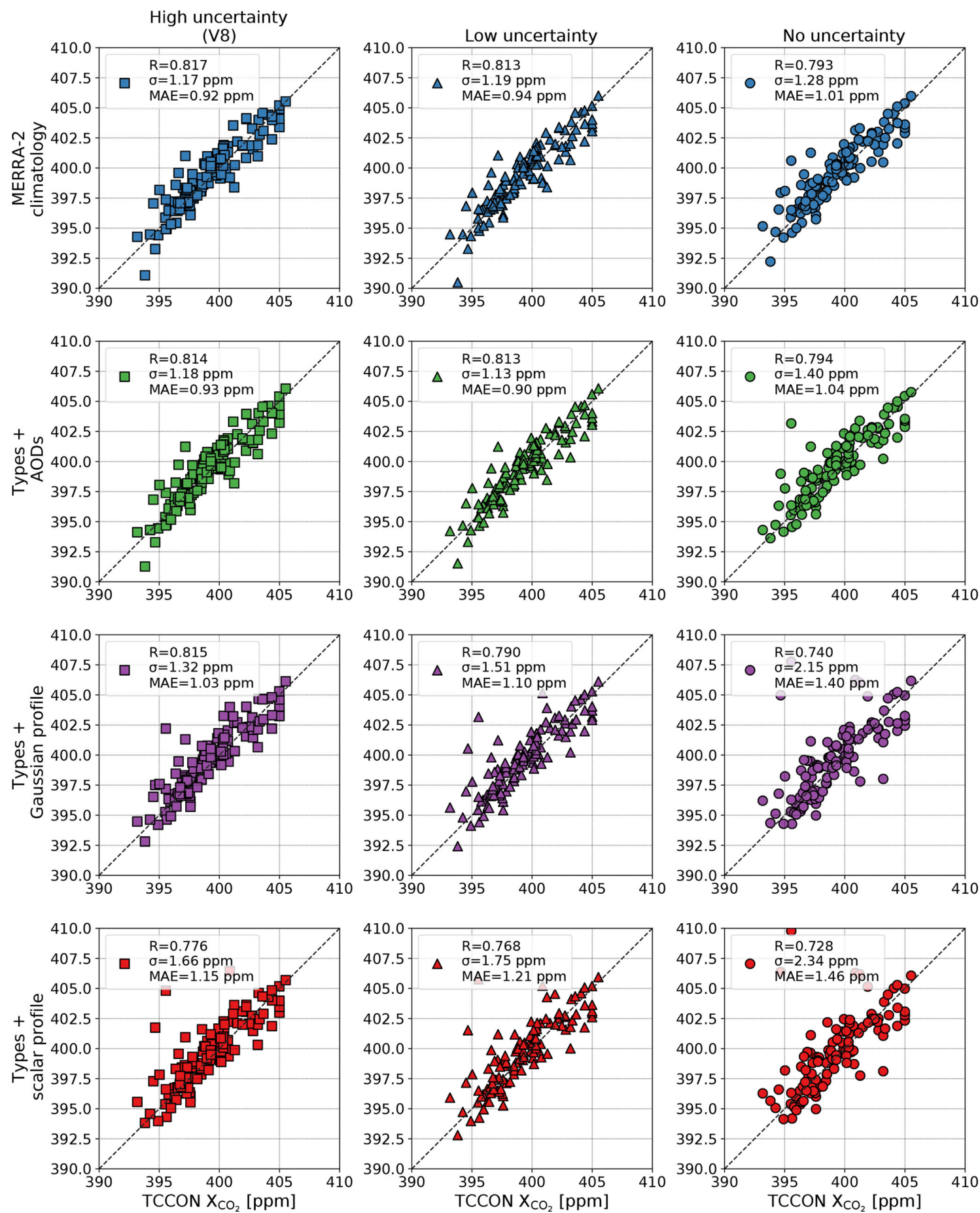

Figure 6. Retrieved OCO-2 $X_{\mathrm{CO}_{2}}$ ( $y$ axes) against TCCON $X_{\mathrm{CO}_{2}}$ ( $x$ axes). Overpass means are plotted. The first row is the operational retrieval (V8). The second row is ingesting GEOS-5 types and AODs, the third row is ingesting GEOS-5 types and Gaussian profile priors, and the fourth row is ingesting GEOS-5 types and solving for a scalar to the prior aerosol profile. The left column is high uncertainty, the middle column is low uncertainty, and the right column is no uncertainty (see Table 2). For each panel, $R$ is the correlation coefficient, $\sigma$ is the standard deviation of the error against TCCON, and MAE is the mean absolute error against TCCON. The TCCON sites used are listed in Table 1, are shown in Fig. 2, and were required to have valid data between 17 September 2014 and 2 May 2016. 

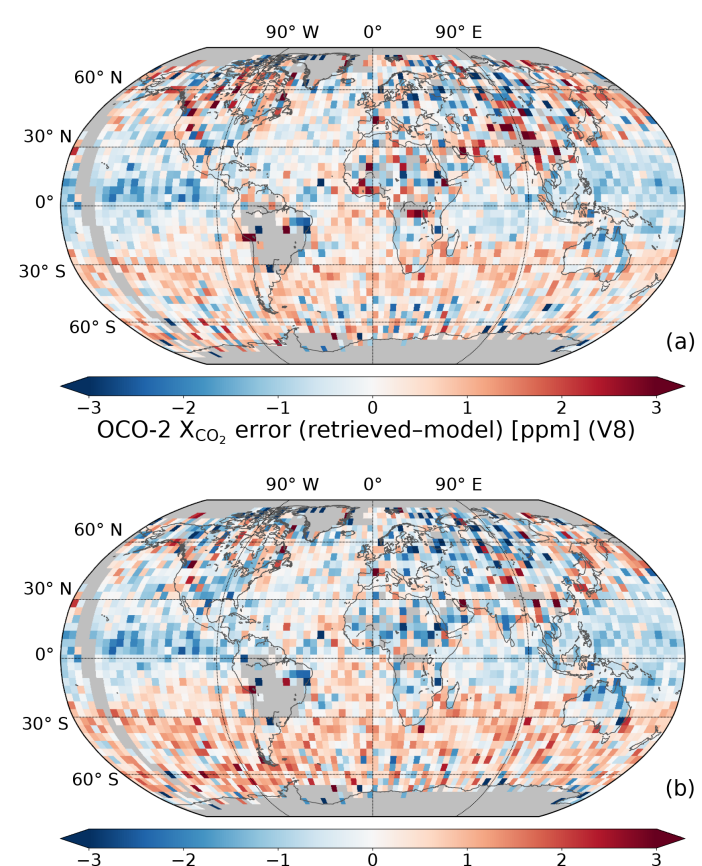

OCO-2 $\mathrm{X}_{\mathrm{CO}_{2}}^{-3}$ error (retrieved-model) [ppm] $\left(\mathrm{V}^{1}+\mathrm{GEOS}^{2}-5\right.$ types $\stackrel{3}{-1}$ and AODs)

Figure 7. (a) The $4^{\circ} \times 4^{\circ}$ binned $X_{\mathrm{CO}_{2}}$ error against model validation for V8. (b) The $4^{\circ} \times 4^{\circ}$ binned $X_{\mathrm{CO}_{2}}$ error against model validation for the GEOS-5 types and AODs with low uncertainty. Grey bins represent no data.

tion comes from the retrieval. This shows the utility of having semi-constrained aerosol priors to guide the $X_{\mathrm{CO}_{2}}$ retrieval algorithm. The only row where the low-uncertainty test does better than the high-uncertainty test is when we ingest types and AODs. This again indicates that it may be beneficial to use GEOS-5 modeled types and AODs and assign them some level of confidence that is greater than the V8 constraint.

\subsection{Model validation results}

While TCCON gives a robust estimate of the statistical errors for our test setups, it does not allow for regional analysis because of the sparsity of the network. The $\mathrm{CO}_{2}$ model median validation technique, described in Sect. 3.2, allows for an assessment of regional errors in the test setups compared to a truth metric. For this work, the most promising aerosol setup in the TCCON validation study was selected for further analysis. That is, ingesting the GEOS-5 types and AODs with low uncertainty. Figure 7 shows the operational (V8) $X_{\mathrm{CO}_{2}}$ error and the GEOS-5 aerosol prior setup $X_{\mathrm{CO}_{2}}$ error while Fig. 8a shows the difference of the absolute value of the $X_{\mathrm{CO}_{2}}$ errors for the two setups.

Here, regional differences can be seen. Over northern Africa and central Asia the operational retrieval (Fig. 7a) is often biased high, which results in a large $X_{\mathrm{CO}_{2}}$ scatter in those regions. The GEOS-5 aerosol setup (Fig. 7b), however, shows that those high-biased bins have mostly been removed.

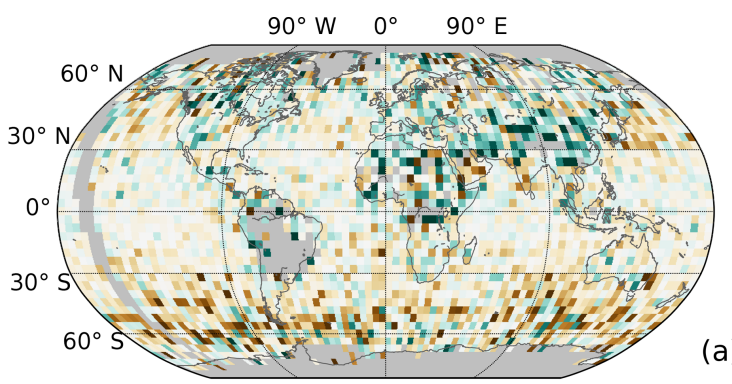

(a)

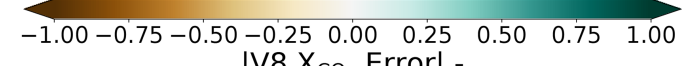

|V8 $\mathrm{X}_{\mathrm{CO}_{2}}$ Error| -

|GEOS-5 types/AODs + low uncertainty $\mathrm{X}_{\mathrm{CO}_{2}}$ error| [ppm]

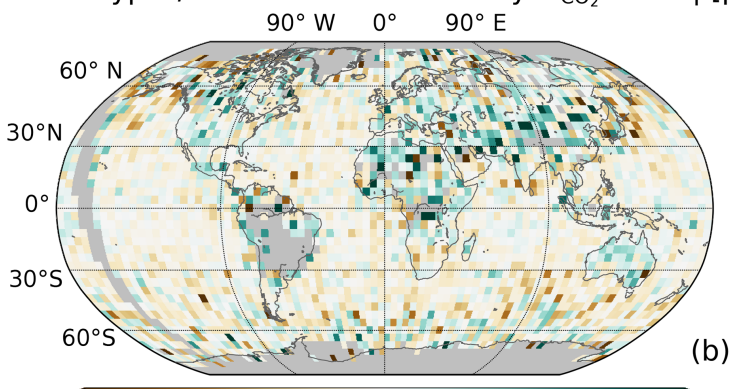

(b)

$-1.00-0.75-0.50-0.250 .00 \quad 0.25 \quad 0.50 \quad 0.75 \quad 1.00$

|V8 $\mathrm{X}_{\mathrm{CO}_{2}}$ error| - |V8 + low uncertainty $\mathrm{X}_{\mathrm{CO}_{2}}$ error| [ppm]

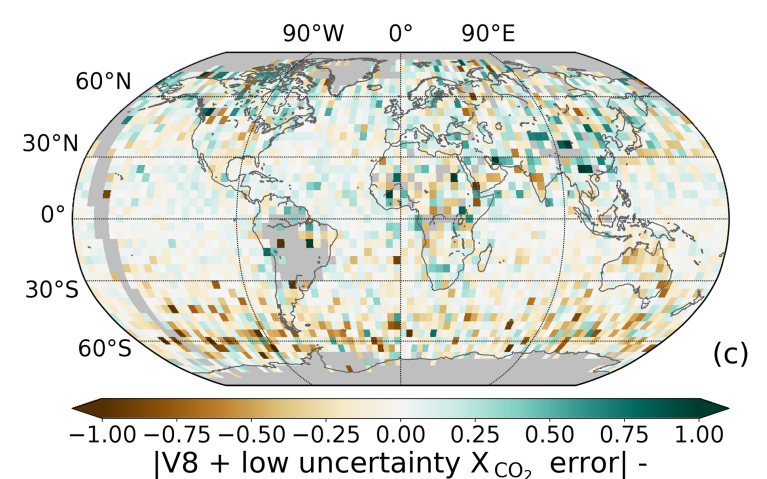

|GEOS-5 types/AODs + low uncertainty $\mathrm{X}_{\mathrm{CO}_{2}}$ error| [ppm]

Figure 8. (a) The $4^{\circ} \times 4^{\circ}$ binned absolute value of $\mathrm{V} 8 X_{\mathrm{CO}_{2}}$ error against the model validation minus the absolute value of the GEOS-5 types and AODs with low-uncertainty $X_{\mathrm{CO}_{2}}$ error against the model validation. (b) The $4^{\circ} \times 4^{\circ}$ binned absolute value of $\mathrm{V} 8$ $X_{\mathrm{CO}_{2}}$ error against the model validation minus the absolute value of V8 with low-uncertainty $X_{\mathrm{CO}_{2}}$ error against the model validation. (c) The $4^{\circ} \times 4^{\circ}$ binned absolute value of V8 with low-uncertainty $X_{\mathrm{CO}_{2}}$ error against the model validation minus the absolute value of GEOS-5 types and AODs with low-uncertainty $X_{\mathrm{CO}_{2}}$ error against the model validation. Green grid cells represent an improvement relative to the model validation while brown grid cells represent a worse comparison to the model validation. Grey bins represent no data.

The difference plot (Fig. 8a) demonstrates an improvement in the error of around $1 \mathrm{ppm}$ for many grid cells in northern Africa and central Asia. An additional regional difference is in the Southern Ocean, where the GEOS-5 aerosol setup de- 
velops a new high bias of $0.4 \mathrm{ppm}$ in many of the bins, compared to V8, which has a bias of nearly zero $(+0.1 \mathrm{ppm})$. Over the remaining land and ocean regions there is minimal change in $X_{\mathrm{CO}_{2}}$ between the two datasets. While of interest, comparing retrieval setups over the Amazon and high latitudes is difficult due to the lack of soundings. This is because these regions are typically cloudy around solar noon or lack the necessary amount of reflected sunlight to make an accurate retrieval, so they have been filtered out.

Regarding the plots just discussed, three factors could be contributing to the regional changes in $\mathrm{X}_{\mathrm{CO}_{2}}$ between $\mathrm{V} 8$ and the GEOS-5 aerosol prior setup. First, the decrease in uncertainty to $25 \%$ of V8. Second, the two selected aerosol types. Third, the modified AOD priors of the two aerosol types. In order to isolate the first effect, Fig. 8b shows a comparison between V8 and V8 with low uncertainty. Here, we can see that the impact of simply reducing the prior uncertainty on the retrieved AODs is substantial and accounts for a considerable portion of the improvement over northern Africa and central Asia, with the standard deviation of the error being reduced from 2.12 to $1.92 \mathrm{ppm}$. The ocean remains nearly unchanged, along with much of the remaining land surface.

Now that we have isolated the impact of reducing uncertainty, we can compare V8 with low uncertainty to GEOS-5 types and AODs with low uncertainty to determine what impact, if any, using the constrained GEOS-5 aerosol types and priors has on the $X_{\mathrm{CO}_{2}}$ error. Figure 8c shows that this change is beneficial over central Asia $\left(\sigma_{X_{\mathrm{CO}_{2}}}\right.$ error reduced from 2.07 to $1.94 \mathrm{ppm}$ for measurements over land between latitudes 16 and $56^{\circ} \mathrm{N}$ and longitudes 52 and $152^{\circ} \mathrm{E}$ ), has a minimal

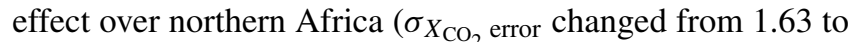
$1.62 \mathrm{ppm}$ for measurements over land between latitudes $6^{\circ} \mathrm{S}$ and $38^{\circ} \mathrm{N}$ and longitudes $20^{\circ} \mathrm{W}$ and $52^{\circ} \mathrm{E}$ ), and has a detrimental effect over the Southern Ocean $\left(\sigma_{X_{\mathrm{CO}_{2}}}\right.$ error increased from 1.86 to $1.95 \mathrm{ppm}$ and a positive bias of $0.4 \mathrm{ppm}$ for measurements south of $45^{\circ} \mathrm{S}$ ). This suggests that the improvement in the scatter of the $X_{\mathrm{CO}_{2}}$ error against model validation over northern Africa was primarily due to the reduction in uncertainty in the prior AODs and not the co-located GEOS-5 aerosol prior types and values themselves. Over central Asia, however, the improvement seems to be a combination of reducing the uncertainty and using instantaneous types and/or AODs. Over the Southern Ocean, using GEOS5 types and prior AODs results in an increase in scatter and a high bias of $0.4 \mathrm{ppm}$.

Next, we attempt to distinguish between the impact of using GEOS-5 aerosol types and using their corresponding AODs as prior information. The areas of interest are central Asia, where using instantaneous priors improved the $X_{\mathrm{CO}_{2}}$ retrieval, and the Southern Ocean, where it worsened the $X_{\mathrm{CO}_{2}}$ retrieval. Figure 9a shows the binned prior AOD for V8, which is derived from a monthly MERRA-2 climatology (as discussed in Sect. 2), while Fig. 9b shows the binned prior AOD for our test setup, which uses the co-located GEOS-5 modeled data. In general, slightly more variation is seen in
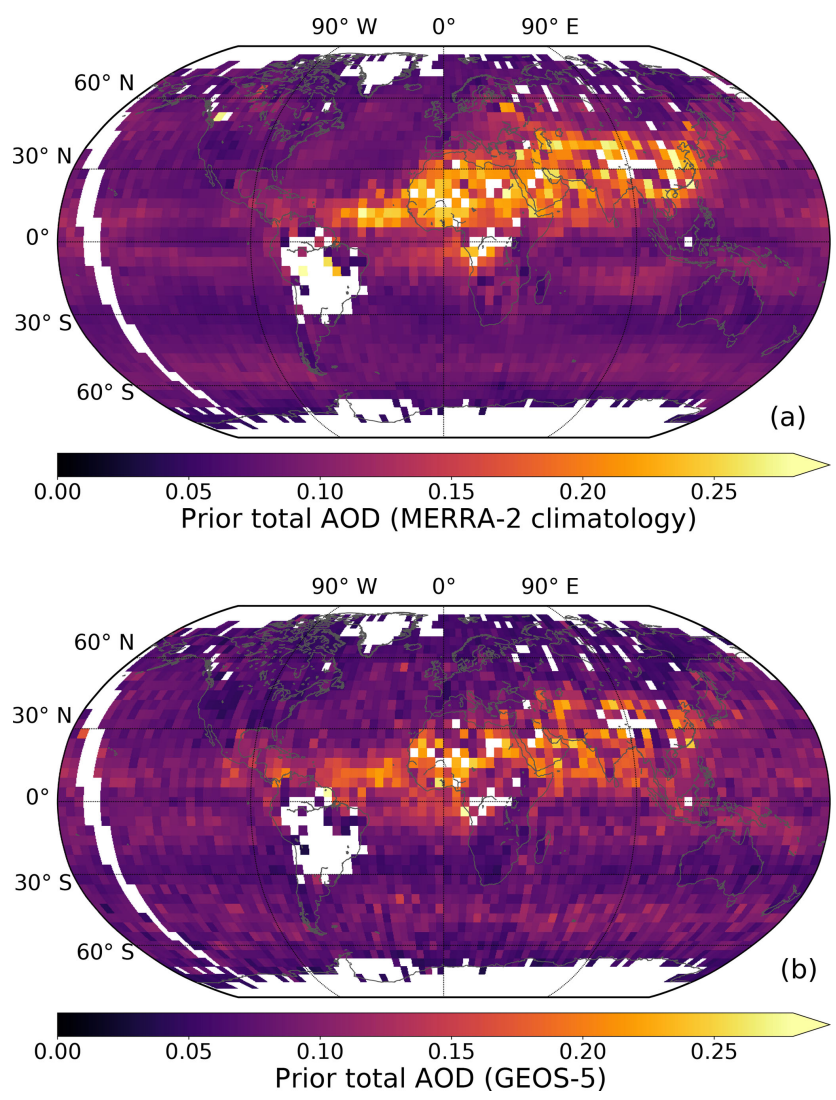

Figure 9. (a) The $4^{\circ} \times 4^{\circ}$ binned prior AOD for V8, derived from a MERRA-2 monthly climatology. (b) The $4^{\circ} \times 4^{\circ}$ binned prior AOD for V8 + GEOS-5 types and AODs with low uncertainty, derived from co-located GEOS-5 AODs. White bins represent no data.

the GEOS-5 priors, which is to be expected, as the monthly climatology is a mean of an entire month and thus removes most synoptic variability. The most prominent change, however, is the significant reduction in prior AOD over northern Africa and central Asia. The GEOS-5 aerosol setup has a $30 \%$ lower mean prior AOD than V8. This is likely because the MERRA-2 climatology was created by simply averaging an entire month of data together, including all instances in which the optical depth was large due to dust storms, pollution events, biomass burning, etc. Those scenes, however, are typically removed by OCO-2's pre-screeners (ABP and IDP, described in Sect. 3.3) before being processed through the retrieval code, and thus the GEOS-5 prior map only includes scenes that were determined to be sufficiently clear to perform retrievals on. This suggests that the MERRA-2 monthly climatology aerosol prior may be artificially high and not entirely appropriate for use in the operational retrieval algorithm. This is also seen in Fig. 3, in which there are several MERRA-2 climatology AODs that are significantly high biased against AERONET. Figure 3, however, shows only data from 13 AERONET sites and is thus not representative of the global differences. 
In optimal estimation the final optimized state vector represents a weighted combination of the prior information and the measurement, not just the state of the prior. Figure 10a shows the retrieved AOD for V8 while Fig. 10b shows the retrieved AOD for the GEOS-5 aerosol setup. Here, we see an even more dramatic difference in retrieved AODs over northern Africa and central Asia. Over land in these two regions, the retrieved AOD is $52 \%$ lower for the GEOS-5 aerosol setup. This is partially due to the reduced uncertainty on the prior AODs for the GEOS-5 aerosol setup, which prevents it from deviating substantially from the prior.

While the differences in $X_{\mathrm{CO}_{2}}$ over central Asia correlate with a large difference in the magnitude of the retrieved AOD, the same cannot be said of the $X_{\mathrm{CO}_{2}}$ differences over the Southern Ocean, as those differences in retrieved AOD are small (8.9\% increase in the GEOS-5 test setup over the Southern Ocean). Additionally, Fig. 8b demonstrated that the reduction in uncertainty alone had a minimal impact on this region.

The changing of one or both of the aerosol types when going from the MERRA-2 monthly climatology to the instantaneous GEOS-5 setup could be the explanation for the positive $0.4 \mathrm{ppm}$ bias in $X_{\mathrm{CO}_{2}}$. Of the 17355 global soundings remaining after post-filtering, $32 \%$ show one or both aerosol types to be different while only $0.7 \%$ show both aerosol types to be different. To test this hypothesis, we ran an additional set of soundings similar to the GEOS-5 types and AODs with low uncertainty but not changing the types. Figure 11 demonstrates that changing the types has almost no effect on the Southern Ocean and overall has a small and sporadic effect (note the reduced scale). The mean difference between ingesting GEOS-5 AODs and types and only ingesting GEOS-5 AODs for soundings in which the type actually changed is about $0.01 \mathrm{ppm}$ with a standard deviation of about $0.2 \mathrm{ppm}$. Only a small fraction of soundings had differences larger than $0.5 \mathrm{ppm}$ ( $2.3 \%$ of all soundings). Thus, the selection of an appropriate AOD prior and uncertainty is much more important than the exact aerosol properties in our retrieval parameterization.

After further investigation, the modification to the stratospheric aerosol prior and its corresponding uncertainty is likely the cause of the Southern Ocean $0.4 \mathrm{ppm}$ high bias in the GEOS-5 aerosol setup. As detailed in O'Dell et al. (2018), ACOS V7 contained a high bias over water at high southern latitudes due to both the presence of stratospheric aerosol from the Calbuco eruption in 2015 and ice buildup on the OCO-2 focal plane arrays. Here, we have unintentionally replicated this issue, as the stratospheric AOD priors from GEOS-5 have a median of around 0.003 , compared to a global prior value of 0.006 used in V8. Figure 12 demonstrates that when V8 solves for a large stratospheric AOD in the Southern Ocean, GEOS-5 cannot because it starts with a lower prior and is unable to sufficiently increase it. This results in a significant positive bias in $X_{\mathrm{CO}_{2}}$ (Fig. 7b). When the retrieved V8 strato-
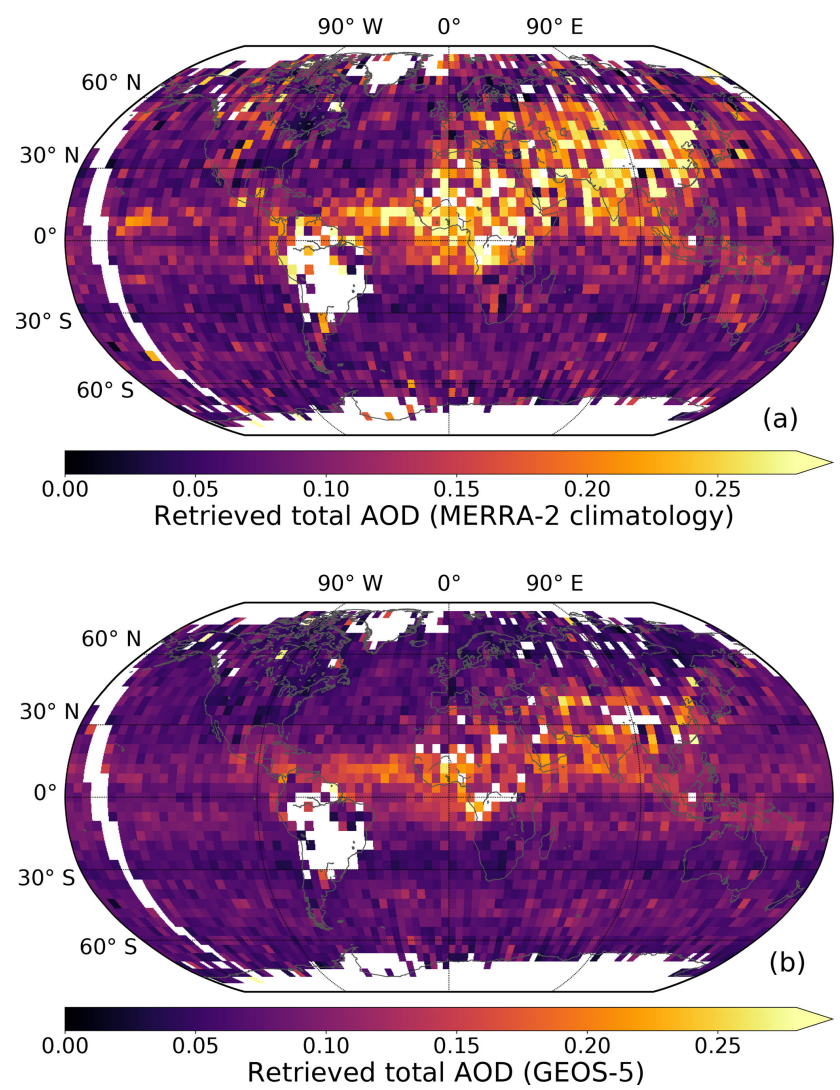

Figure 10. (a) The $4^{\circ} \times 4^{\circ}$ binned retrieved AOD for V8. (b) The $4^{\circ} \times 4^{\circ}$ binned retrieved AOD for V8 + GEOS-5 types and AODs with low uncertainty. White bins represent no data.

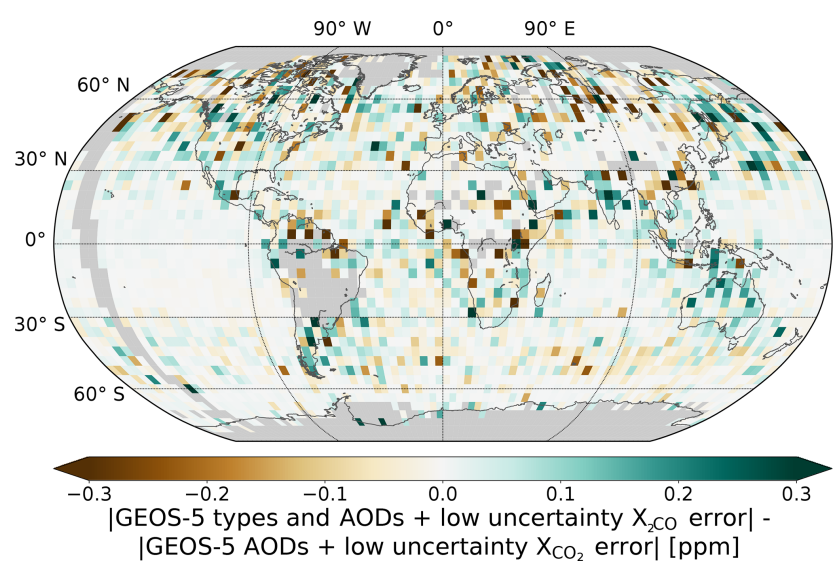

Figure 11. The $4^{\circ} \times 4^{\circ}$ binned absolute value of GEOS-5 types and AODs with low-uncertainty $X_{\mathrm{CO}_{2}}$ error against the model validation minus the absolute value of GEOS-5 AODs with lowuncertainty $X_{\mathrm{CO}_{2}}$ error against the model validation. Green grid cells represent an improvement relative to the model validation while brown grid cells represent a worse comparison to the model validation. Grey bins represent no data. 


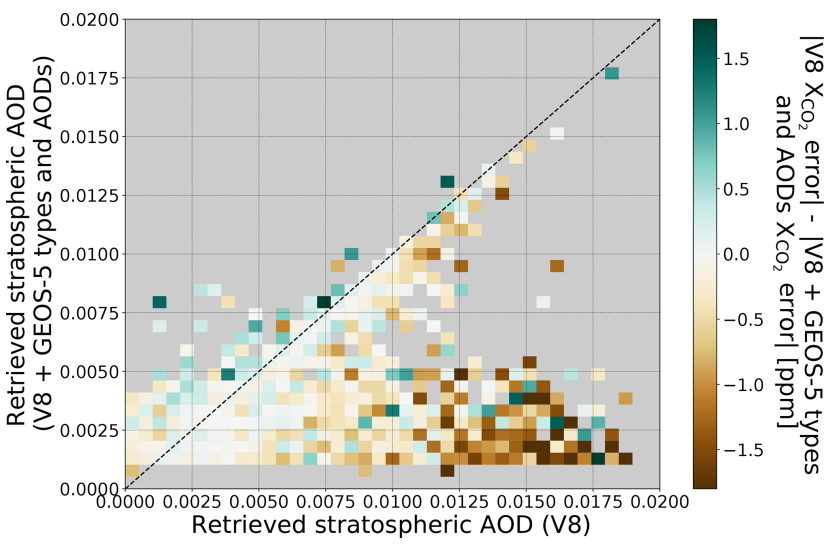

Figure 12. Retrieved stratospheric AOD from V8 versus retrieved stratospheric AOD from V8 + GEOS-5 types and AODs with low uncertainty for the Southern Ocean. Color represents the change in the absolute value of the $X_{\mathrm{CO}_{2}}$ error between the two retrieval types, for which green demonstrates an improvement over V8 and brown represents a worsening.

spheric AOD is greater than 0.012 in the Southern Ocean, the GEOS-5 aerosol setup incurs a positive bias of approximately $1.4 \mathrm{ppm}$ (compared to the positive $0.4 \mathrm{ppm}$ bias for all Southern Ocean retrievals). This indicates that in soundings in which large stratospheric AODs are needed to fit the radiances, the lack of AOD usually appears to lead to a high bias in $X_{\mathrm{CO}_{2}}$.

To further test this hypothesis, we ran a set of soundings in which we reverted the stratospheric aerosol prior AOD and prior uncertainty back to $\mathrm{V} 8$ values $(0.006$ and a $1 \sigma$ uncertainty on the $\ln (\mathrm{AOD})$ of 1.8 ). This revealed that the $0.4 \mathrm{ppm}$ bias in the Southern Ocean mostly disappears, as the high bias is reduced back to approximately $+0.1 \mathrm{ppm}$, in agreement with V8.

\section{Discussion and conclusions}

In this study we investigated the impact of using better informed aerosol priors in the OCO-2 ACOS $X_{\mathrm{CO}_{2}}$ retrieval algorithm applied to real measurements. We ingested aerosol information from co-located GEOS-5 model data with varying levels of uncertainty and compared to two validation sources, TCCON and a global $\mathrm{CO}_{2}$ model suite.

We found that ingesting instantaneous AOD information with low uncertainty slightly reduced the standard deviation of the $X_{\mathrm{CO}_{2}}$ error against TCCON from 1.17 to $1.13 \mathrm{ppm}$. More interestingly, we found that attempting to ingest vertical information from GEOS-5 produced poor results against TCCON, with mean absolute errors more than $50 \%$ larger than V8. We hypothesize that this is because accurate vertical placement of aerosol layers still represents a significant challenge in global aerosol models (Koffi et al., 2016). This is due to the large uncertainty in processes related to

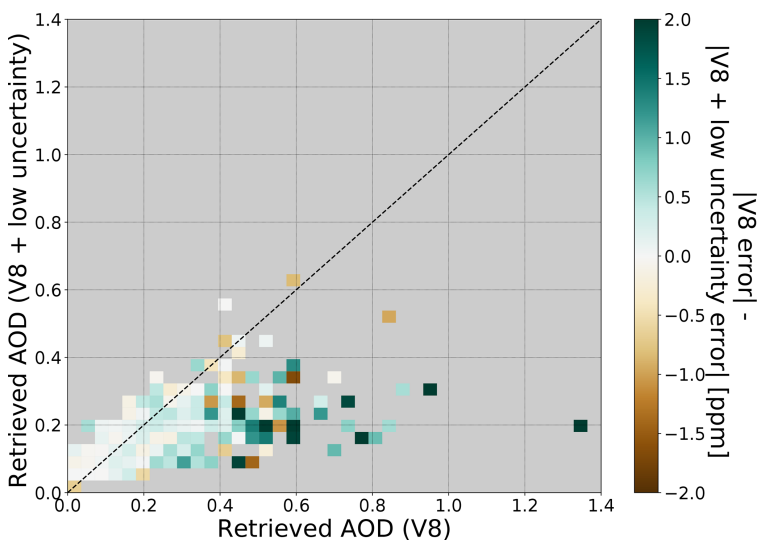

Figure 13. Retrieved AOD from V8 versus retrieved AOD from V8 with low uncertainty for northern Africa and central Asia. Color represents the change in the absolute value of the $X_{\mathrm{CO}_{2}}$ error between the two retrieval types, for which green demonstrates an improvement over V8 and brown represents a worsening.

how aerosols are distributed vertically, partially because of the lack of constraint by global observations (Kipling et al., 2016). Additionally, fixing the ingested aerosol information also makes the retrieval compare poorly to TCCON. This is, again, because the priors will always be imperfect, so the OCO-2 ACOS $X_{\mathrm{CO}_{2}}$ retrieval algorithm needs some amount of freedom to adjust the radiances.

A comparison to our model validation dataset reveals an improvement over northern Africa and central Asia when using the GEOS-5 types and AODs with low uncertainty compared to $\mathrm{V} 8$, with the scatter in $X_{\mathrm{CO}_{2}}$ error being reduced from 2.12 to $1.83 \mathrm{ppm}$. Additionally, we see a new high bias in $X_{\mathrm{CO}_{2}}$ of $0.4 \mathrm{ppm}$ over the Southern Ocean. These regional differences in OCO-2 V8 compared to the GEOS-5 type and AOD low-uncertainty prior test setup are likely caused by one of the three modifications. First, reducing the uncertainty on the prior AODs in V8 results in an improvement over northern Africa and central Asia. Figure 13 shows that by constraining the prior AODs in V8, we prevent the algorithm from retrieving large AODs. Those soundings that retrieved large AODs in V8 but smaller AODs in the low-uncertainty setup generally have smaller $X_{\mathrm{CO}_{2}}$ errors (green pixels in Fig. 13). For soundings in which the retrieved V8 AOD is greater than 0.4 over northern Africa and central Asia, constraining the prior AODs with low uncertainty reduces the $X_{\mathrm{CO}_{2}}$ bias against the validation dataset by $0.55 \mathrm{ppm}$ on average. Some soundings are outliers, in that they do worse when constrained (brown pixels in Fig. 13). Around $8 \%$ of the retrievals have an $X_{\mathrm{CO}_{2}}$ error increase of greater than $0.5 \mathrm{ppm}$. This may be because those scenes actually contain large AODs and thus constraining the priors is hindering the retrieval's ability to properly fit the radiances, but further investigation is needed on this topic. 
Second, some of the high bias seen in V8 (Fig. 7a) is likely due to the MERRA-2 climatological priors being unrealistically high for the selected OCO-2 soundings. Physically, when there are AODs retrieved that are too large in magnitude, the $\mathrm{CO}_{2}$ absorption lines are filled in too much by the retrieval because it thinks those photons are experiencing a shorter path length than they are in reality. The retrieval then must add more $\mathrm{CO}_{2}$ to deepen the absorption lines again to match the measured line depths. This results in the observed high bias in V8 over central Asia, which is mostly removed when smaller, more appropriate AOD priors are taken from the GEOS-5 dataset (Fig. 8c). However, Fig. 8c also showed that using lower AOD priors alone had no significant net impact on northern Africa. This difference may be due to northern Africa having a higher surface albedo than central Asia. This results in a larger fraction of the signal coming from the surface and less weight placed on any aerosols present. So long as the retrieved AODs are not very large, as discussed above, the $X_{\mathrm{CO}_{2}}$ results over northern Africa may be less sensitive to the aerosol prior than other regions.

Third, the GEOS-5 types and AODs with low uncertainty resulted in a new high bias of $0.4 \mathrm{ppm}$ in $X_{\mathrm{CO}_{2}}$ relative to V8 over the Southern Ocean. It was initially hypothesized that the change in aerosol types may have caused the high bias, but we showed that changing one or both of the aerosol types has a minimal impact on the $X_{\mathrm{CO}_{2}}$ in this setup. After additional tests, we found that the GEOS-5 stratospheric AODs in the Southern Ocean were too small to be able to account for actual stratospheric aerosol in the region along with the effects of an ice accumulation artifact in the OCO-2 radiances. Reverting the stratospheric prior and uncertainty back to that of V8 mostly eliminated the high bias in the Southern Ocean. This conclusion highlights the severe impact that even a small amount of aerosol can have on the retrieved $X_{\mathrm{CO}_{2}}$.

This work is relevant for several missions set to launch in the near future, including OCO-3, GOSAT-2, MicroCarb, TanSat-2, and GeoCarb. Algorithm development teams will have to decide how they will account for clouds and aerosols in order to minimize errors in their $\mathrm{CO}_{2}$ measurements. While we have shown the benefits and limitations of using instantaneous modeled aerosol data to inform the OCO-2 $X_{\mathrm{CO}_{2}}$ retrieval, more work is needed to determine the optimal aerosol parameterization for near-infrared measurements of $\mathrm{CO}_{2}$. These results may be of use in guiding development for the next version of the OCO-2 ACOS $X_{\mathrm{CO}_{2}}$ retrieval algorithm.

Data availability. The OCO-2 L2 Full Physics Code is open source and available on GitHub https://github. com/nasa/RtRetrievalFramework (last access: 27 February 2019), and the user's guide for it is available at http://nasa.github.io/RtRetrievalFrameworkDoc/ (last access: 27 February 2019). All of the OCO-2 data products are pub- licly available through the NASA Goddard Earth Science Data and Information Services Center (GES DISC) for distribution and archiving (http://disc.sci.gsfc.nasa.gov/OCO-2; last access: 27 February 2019). TCCON data were obtained from the TCCON data archive hosted by CaltechDATA and are available from https://tccondata.org/ (last access: 27 February 2019).

Author contributions. $\mathrm{RN}$ and $\mathrm{CO}$ developed the hypotheses and designed the experiments, $\mathrm{RN}$ performed the retrievals, and $\mathrm{RN}$ and $\mathrm{CO}$ analyzed the results.

Competing interests. The authors declare that they have no conflict of interest.

Acknowledgements. The authors would like to thank Thomas E. Taylor of Colorado State University and Aronne Merrelli of the University of Wisconsin-Madison for their contributions to this work. This work was funded by NASA Jet Propulsion Laboratory OCO-2 subcontract no. 5359007. TCCON data were obtained from the TCCON Data Archive, hosted by the Caltech Library Research Data Repository - https://tccondata.org/ (last access: 27 February 2019). The Caltech, Lamont, and Park Falls TCCON stations are funded by NASA grants NNX14AI60G, NNX11AG01G, NAG5-12247, and NNG05-GD07G and the NASA Orbiting Carbon Observatory. The Darwin TCCON station is funded by NASA grants NAG5-12247 and NNG05-GD07G and the Australian Research Council grants DP140101552, DP110103118, DP0879468, and LP0562346. The Orléans TCCON station is funded by the EU projects InGOS and ICOS-INWIRE, by the Senate of Bremen and by the RAMCES team at LSCE. The Paris TCCON station is supported by UPMC.

Edited by: Piet Stammes

Reviewed by: François-Marie Bréon and one anonymous referee

\section{References}

Aben, I., Hasekamp, O., and Hartmann, W.: Uncertainties in the space-based measurements of $\mathrm{CO}_{2}$ columns due to scattering in the Earth's atmosphere, J. Quant. Spectrosc. Ra., 104, 450-459, https://doi.org/10.1016/j.jqsrt.2006.09.013, 2007.

Baker, D. F., Bösch, H., Doney, S. C., O’Brien, D., and Schimel, D. S.: Carbon source/sink information provided by column $\mathrm{CO}_{2}$ measurements from the Orbiting Carbon Observatory, Atmos. Chem. Phys., 10, 4145-4165, https://doi.org/10.5194/acp-104145-2010, 2010.

Basu, S., Guerlet, S., Butz, A., Houweling, S., Hasekamp, O., Aben, I., Krummel, P., Steele, P., Langenfelds, R., Torn, M., Biraud, S., Stephens, B., Andrews, A., and Worthy, D.: Global $\mathrm{CO}_{2}$ fluxes estimated from GOSAT retrievals of total column $\mathrm{CO}_{2}$, Atmos. Chem. Phys., 13, 8695-8717, https://doi.org/10.5194/acp13-8695-2013, 2013.

Butz, A., Hasekamp, O. P., Frankenberg, C., and Aben, I.: Retrievals of atmospheric $\mathrm{CO}_{2}$ from simulated space-borne 
measurements of backscattered near-infrared sunlight: accounting for aerosol effects, Appl. Optics, 48, 3322-3336, https://doi.org/10.1364/AO.48.003322, 2009.

Butz, A., Guerlet, S., Hasekamp, O., Schepers, D., Galli, A., Aben, I., Frankenberg, C., Hartmann, J.-M., Tran, H., Kuze, A., Keppel-Aleks, G., Toon, G., Wunch, D., Wennberg, P., Deutscher, N., Griffith, D., Macatangay, R., Messerschmidt, J., Notholt, J., and Warneke, T.: Toward accurate $\mathrm{CO}_{2}$ and $\mathrm{CH}_{4}$ observations from GOSAT, Geophys. Res. Lett., 38, L14812, https://doi.org/10.1029/2011GL047888, 2011.

Chevallier, F., Bréon, F.-M., and Rayner, P. J.: Contribution of the Orbiting Carbon Observatory to the estimation of $\mathrm{CO}_{2}$ sources and sinks: Theoretical study in a variational data assimilation framework, J. Geophys. Res., 112, D09307, https://doi.org/10.1029/2006JD007375, 2007.

Chevallier, F., Maksyutov, S., Bousquet, P., Bréon, F.-M., Saito, R., Toshida, Y., and Yokota, T.: On the accuracy of the $\mathrm{CO}_{2}$ surface fluxes to be estimated from the GOSAT observations, Geophys. Res. Lett., 36, L19807, https://doi.org/10.1029/2009GL040108, 2009.

Chevallier, F., Palmer, P. I., Feng, L., Boesch, H., O’Dell, C. W., and Bousquet, P.: Toward robust and consistent regional $\mathrm{CO}_{2}$ flux estimates from in situ and spaceborne measurements of atmospheric $\mathrm{CO}_{2}$, Geophys. Res. Lett., 41, 1065-1070, https://doi.org/10.1002/2013GL058772, 2014.

Connor, B. J., Boesch, H., Toon, G., Sen, B., Miller, C., and Crisp, D.: Orbiting Carbon Observatory: Inverse method and prospective error analysis, J. Geophys. Res., 113, D05305, https://doi.org/10.1029/2006JD008336, 2008.

Crisp, D., Miller, C. E., and DeCola, P. L.: NASA Orbiting Carbon Observatory: measuring the column averaged carbon dioxide mole fraction from space, J. Appl. Remote Sens., 2, 023508, https://doi.org/10.1117/1.2898457, 2008.

Crisp, D., Boesch, H., Brown, L., Castano, R., Christi, M., Connor, B., Frankenberg, C., McDuffie, J., Miller, C. E., Natraj, V., O’Dell, C., O’Brien, D., Polonsky, I., Oyafuso, F., Thompson, D., Toon, G., and Spurr, R.: OCO (Orbiting Carbon Observatory)-2 Level 2 Full Physics Retrieval Algorithm Theoretical Basis, Tech. Rep. OCO D-65488, Tech. rep., NASA Jet Propulsion Laboratory, California Institute of Technology, Pasadena, CA, version 1.0 Rev 4, available at: https://docserver.gesdisc.eosdis.nasa.gov/public/project/ OCO/OCO-2_L2_FP_ATBD_v1_rev4_Nov10.pdf (last access: 27 February 2019), 2010.

Crowell, S. M. R., Kawa, S. R., Browell, E. V., Hammerling, D. M., Moore, B., Schaefer, K., and Doney, S. C.: On the Ability of Space-Based Passive and Active Remote Sensing Observations of $\mathrm{CO}_{2}$ to Detect Flux Perturbations to the Carbon Cycle, J. Geophys. Res.-Atmos., 123, 1460-1477, https://doi.org/10.1002/2017JD027836, 2018.

Dubey, M., Parker, H., Henderson, B., Green, D., Butterfield, Z., Keppel-Aleks, G., Allen, N., Blavier, J.-F., Roehl, C., Wunch, D., and Lindenmaier, R.: TCCON data from Manaus (BR), Release GGG2014.R0, TCCON Data Archive, hosted by CaltechDATA, https://doi.org/10.14291/tccon.ggg2014.manaus01.R0/1149274, 2014.

Dubovik, O., Lapyonok, T., Kaufman, Y. J., Chin, M., Ginoux, P., Kahn, R. A., and Sinyuk, A.: Retrieving global aerosol sources from satellites using inverse modeling, Atmos. Chem. Phys., 8, 209-250, https://doi.org/10.5194/acp-8-209-2008, 2008.

Feist, D. G., Arnold, S. G., John, N., and Geibel, M. C.: TCCON data from Ascension Island (SH), Release GGG2014.R0, TCCON Data Archive, hosted by CaltechDATA, https://doi.org/10.14291/tccon.ggg2014.ascension01.R0/1149285, 2014.

Feng, L., Palmer, P. I., Yang, Y., Yantosca, R. M., Kawa, S. R., Paris, J.-D., Matsueda, H., and Machida, T.: Evaluating a 3-D transport model of atmospheric $\mathrm{CO}_{2}$ using ground-based, aircraft, and space-borne data, Atmos. Chem. Phys., 11, 27892803, https://doi.org/10.5194/acp-11-2789-2011, 2011.

Frankenberg, C., Platt, U., and Wagner, T.: Iterative maximum a posteriori (IMAP)-DOAS for retrieval of strongly absorbing trace gases: Model studies for $\mathrm{CH}_{4}$ and $\mathrm{CO}_{2}$ retrieval from near infrared spectra of SCIAMACHY onboard ENVISAT, Atmos. Chem. Phys., 5, 9-22, https://doi.org/10.5194/acp-5-92005, 2005.

Frankenberg, C., Hasekamp, O., O’Dell, C., Sanghavi, S., Butz, A., and Worden, J.: Aerosol information content analysis of multiangle high spectral resolution measurements and its benefit for high accuracy greenhouse gas retrievals, Atmos. Meas. Tech., 5, 1809-1821, https://doi.org/10.5194/amt-5-1809-2012, 2012.

Griffith, D. W. T., Deutscher, N. M., Velazco, V. A., Wennberg, P. O., Yavin, Y., Keppel-Aleks, G., Washenfelder, R., Toon, G. C., Blavier, J.-F., Paton-Walsh, C., Jones, N. B., Kettlewell, G. C., Connor, B., Macatangay, R. C., Roehl, C., Ryczek, M., Glowacki, J., Culgan, T., and Bryant, G.: TCCON data from Darwin (AU), Release GGG2014.R0, TCCON Data Archive, hosted by CaltechDATA, https://doi.org/10.14291/tccon.ggg2014.darwin01.R0/1149290, 2014.

Hase, F., Blumenstock, T., Dohe, S., Gross, J., and Kiel, M.: TCCON data from Karlsruhe (DE), Release GGG2014.R1, TCCON Data Archive, hosted by CaltechDATA, https://doi.org/10.14291/tccon.ggg2014.karlsruhe01.R1/1182416, 2015.

Holben, B. N., Eck, T. F., Slutsker, I., Tanré, D., Buis, J., Setzer, A., Vermote, E., Reagan, J. A., Kaufman, Y. J., Nakajima, T., Lavenu, F., Jankowiak, I., and Smirnov, A.: AERONET - A Federated Instrument Network and Data Archive for Aerosol Characterization, Remote Sens. Environ., 66, 1-16, https://doi.org/10.1016/S0034-4257(98)00031-5, 1998.

Inness, A., Baier, F., Benedetti, A., Bouarar, I., Chabrillat, S., Clark, H., Clerbaux, C., Coheur, P., Engelen, R. J., Errera, Q., Flemming, J., George, M., Granier, C., Hadji-Lazaro, J., Huijnen, V., Hurtmans, D., Jones, L., Kaiser, J. W., Kapsomenakis, J., Lefever, K., Leitão, J., Razinger, M., Richter, A., Schultz, M. G., Simmons, A. J., Suttie, M., Stein, O., Thépaut, J.-N., Thouret, V., Vrekoussis, M., Zerefos, C., and the MACC team: The MACC reanalysis: an $8 \mathrm{yr}$ data set of atmospheric composition, Atmos. Chem. Phys., 13, 4073-4109, https://doi.org/10.5194/acp13-4073-2013, 2013.

Iraci, L. T., Podolske, J., Hillyard, P. W., Roehl, C., Wennberg, P. O., Blavier, J.-F., Allen, N., Wunch, D., Osterman, G., and Albertson, R.: TCCON data from Edwards (US), Release GGG2014.R1, TCCON Data Archive, hosted by CaltechDATA, https://doi.org/10.14291/tccon.ggg2014.edwards01.R1/1255068, 2016. 
Kaufman, Y. J., Tanré, D., Remer, L. A., Vermote, E., Chu, A., and Holben, B.: Operational remote sensing of tropospheric aerosol over land from EOS moderate resolution imaging spectroradiometer, J. Geophys. Res.-Atmos., 102, 17051-17067, https://doi.org/10.1029/96JD03988, 1997.

Kawakami, S., Ohyama, H., Arai, K., Okumura, H., Taura, C., Fukamachi, T., and Sakashita, M.: TCCON data from Saga (JP), Release GGG2014.R0, TCCON Data Archive, hosted by CaltechDATA, https://doi.org/10.14291/tccon.ggg2014.saga01.R0/1149283, 2014.

Kipling, Z., Stier, P., Johnson, C. E., Mann, G. W., Bellouin, N., Bauer, S. E., Bergman, T., Chin, M., Diehl, T., Ghan, S. J., Iversen, T., Kirkevåg, A., Kokkola, H., Liu, X., Luo, G., van Noije, T., Pringle, K. J., von Salzen, K., Schulz, M., Seland, Ø., Skeie, R. B., Takemura, T., Tsigaridis, K., and Zhang, K.: What controls the vertical distribution of aerosol? Relationships between process sensitivity in HadGEM3-UKCA and inter-model variation from AeroCom Phase II, Atmos. Chem. Phys., 16, 2221-2241, https://doi.org/10.5194/acp-16-2221-2016, 2016.

Kivi, R. and Heikkinen, P.: Fourier transform spectrometer measurements of column $\mathrm{CO}_{2}$ at Sodankylä, Finland, Geosci. Instrum. Method. Data Syst., 5, 271-279, https://doi.org/10.5194/gi-5-271-2016, 2016.

Koffi, B., Schulz, M., Bréon, F.-M., Dentener, F., Steensen, B. M., Griesfeller, J., Winker, D., Balkanski, Y., Bauer, S. E., Bellouin, N., Bernsten, T., Bian, H., Chin, M., Diehl, T., Easter, R., Ghan, S., Hauglustaine, D. A., Iversen, T., Kirkevåg, A., Liu, X., Lohmann, U., Myhre, G., Rasch, P., Seland, Ø., Skeie, R. B., Steenrod, S. D., Stier, P., Tackett, J., Takemura, T., Tsigaridis, K., Vuolo, M. R., Yoon, J., and Zhang, K.: Evaluation of the aerosol vertical distribution in global aerosol models through comparison against CALIOP measurements: AeroCom phase II results, J. Geophys. Res.-Atmos., 121, 7254-7283, https://doi.org/10.1002/2015JD024639, 2016.

Kuang, Z., Margolis, J., Toon, G., Crisp, D., and Yung, Y.: Spaceborne measurements of atmospheric $\mathrm{CO}_{2}$ by highresolution NIR spectrometry of reflected sunlight: An introductory study, Geophys. Res. Lett., 15, 11-1-11-4, https://doi.org/10.1029/2001GL014298, 2002.

L'Ecuyer, T. S. and Jiang, J. H.: Touring the atmosphere aboard the A-Train, Phys. Today, 63, 36-41, https://doi.org/10.1063/1.3463626, 2010.

Le Quéré, C., Raupach, M. R., Canadell, J. G., Marland, G., Bopp, L., Ciais, P., Conway, T. J., Doney, S. C., Feely, R. A., Foster, P., Friedlingstein, P., Gurney, K., Houghton, R. A., House, J. I., Huntingford, C., Levy, P. E., Lomas, M. R., Majkut, J., Metzl, N., Ometto, J. P., Peters, G. P., Prentice, I. C., Randerson, J. T., Running, S. W., Sarmiento, J. L., Schuster, U., Sitch, S., Takahashi, T., Viovy, N., van der Werf, G. R., and Woodward, F. I.: Trends in the sources and sinks of carbon dioxide, Nat. Geosci., 2, 831-836, https://doi.org/10.1038/ngeo689, 2009.

Liu, J., Bowman, K. W., Schimel, D. S., Parazoo, N. C., Jiang, Z., Lee, M., Bloom, A. A., Wunch, D., Frankenberg, C., Sun, Y., O’Dell, C. W., Gurney, K. R., Menemenlis, D., Gierach, M., Crisp, D., and Eldering, A.: Contrasting carbon cycle responses of the tropical continents to the 2015-2016 El Niño, Science, 358, 191, https://doi.org/10.1126/science.aam5690, 2017.
Mann, G. W., Carslaw, K. S., Reddington, C. L., Pringle, K. J., Schulz, M., Asmi, A., Spracklen, D. V., Ridley, D. A., Woodhouse, M. T., Lee, L. A., Zhang, K., Ghan, S. J., Easter, R. C., Liu, X., Stier, P., Lee, Y. H., Adams, P. J., Tost, H., Lelieveld, J., Bauer, S. E., Tsigaridis, K., van Noije, T. P. C., Strunk, A., Vignati, E., Bellouin, N., Dalvi, M., Johnson, C. E., Bergman, T., Kokkola, H., von Salzen, K., Yu, F., Luo, G., Petzold, A., Heintzenberg, J., Clarke, A., Ogren, J. A., Gras, J., Baltensperger, U., Kaminski, U., Jennings, S. G., O’Dowd, C. D., Harrison, R. M., Beddows, D. C. S., Kulmala, M., Viisanen, Y., Ulevicius, V., Mihalopoulos, N., Zdimal, V., Fiebig, M., Hansson, H.-C., Swietlicki, E., and Henzing, J. S.: Intercomparison and evaluation of global aerosol microphysical properties among AeroCom models of a range of complexity, Atmos. Chem. Phys., 14, 4679-4713, https://doi.org/10.5194/acp-14-4679-2014, 2014.

Martonchik, J. V., Diner, D. J., Kahn, R. A., Ackerman, T. P., Verstraete, M. M., Pinty, B., and Gordon, H. R.: Techniques for the retrieval of aerosol properties over land and ocean using multiangle imaging, IEEE T. Geosci. Remote, 36, 1212-1227, https://doi.org/10.1109/36.701027, 1998.

Miller, C. E., Crisp, D., DeCola, P. L., Olsen, S. C., Randerson, J. T., Michalak, A. M., Alkhaled, A., Rayner, P., Jacob, D. J., Suntharalingam, P., Jones, D. B. A., Denning, A. S., Nicholls, M. E., Doney, S. C., Pawson, S., Boesch, H., Connor, B. J., Fung, I. Y., O’Brien, D., Salawitch, R. J., Sander, S. P., Sen, B., Tans, P., Toon, G. C., Wennberg, P. O., Wofsy, S. C., Yung, Y. L., and Law, R. M.: Precision requirements for space-based $X_{\mathrm{CO}_{2}}$ data, J. Geophys. Res., 112, D10314, https://doi.org/10.1029/2006JD007659, 2007.

Nelson, R. R., O’Dell, C. W., Taylor, T. E., Mandrake, L., and Smyth, M.: The potential of clear-sky carbon dioxide satellite retrievals, Atmos. Meas. Tech., 9, 1671-1684, https://doi.org/10.5194/amt-9-1671-2016, 2016.

O'Brien, D. M. and Rayner, P. J.: Global observations of the carbon budget $2 . \mathrm{CO}_{2}$ column from differential absorption of reflected sunlight in the $1.61 \mu \mathrm{m}$ band of $\mathrm{CO}_{2}$, J. Geophys. Res., 107, 4354, https://doi.org/10.1029/2001JD000617, 2002.

O’Dell, C. W., Connor, B., Bösch, H., O’Brien, D., Frankenberg, C., Castano, R., Christi, M., Eldering, D., Fisher, B., Gunson, M., McDuffie, J., Miller, C. E., Natraj, V., Oyafuso, F., Polonsky, I., Smyth, M., Taylor, T., Toon, G. C., Wennberg, P. O., and Wunch, D.: The $\mathrm{ACOS} \mathrm{CO}_{2}$ retrieval algorithm - Part 1: Description and validation against synthetic observations, Atmos. Meas. Tech., 5, 99-121, https://doi.org/10.5194/amt-5-99-2012, 2012.

O’Dell, C. W., Eldering, A., Wennberg, P. O., Crisp, D., Gunson, M. R., Fisher, B., Frankenberg, C., Kiel, M., Lindqvist, H., Mandrake, L., Merrelli, A., Natraj, V., Nelson, R. R., Osterman, G. B., Payne, V. H., Taylor, T. E., Wunch, D., Drouin, B. J., Oyafuso, F., Chang, A., McDuffie, J., Smyth, M., Baker, D. F., Basu, S., Chevallier, F., Crowell, S. M. R., Feng, L., Palmer, P. I., Dubey, M., García, O. E., Griffith, D. W. T., Hase, F., Iraci, L. T., Kivi, R., Morino, I., Notholt, J., Ohyama, H., Petri, C., Roehl, C. M., Sha, M. K., Strong, K., Sussmann, R., Te, Y., Uchino, O., and Velazco, V. A.: Improved retrievals of carbon dioxide from Orbiting Carbon Observatory-2 with the version 8 ACOS algorithm, Atmos. Meas. Tech., 11, 6539-6576, https://doi.org/10.5194/amt11-6539-2018, 2018.

Oshchepkov, S., Bril, A., and Yokota, T.: PPDF-based method to account for atmospheric light scattering in observations of 
carbon dioxide from space, J. Geophys. Res., 113, D23210, https://doi.org/10.1029/2008JD010061, 2008.

Osterman, G., Eldering, A., Mandrake, L., O’Dell, C., Wunch, D., Wennberg, P. O., Fischer, B., and Marchetti, Y.: Orbiting Carbon Observatory-2 (OCO-2) Lite Files, Bias Correction, and Warn Level, Tech. rep., NASA Jet Propulsion Laboratory, California Institute of Technology, Pasadena, CA, version 2.0, available at: https://docserver.gesdisc.eosdis.nasa.gov/public/project/ OCO/OCO2_XCO2_Lite_Files_and_Bias_Correction.pdf (last access: 27 February 2019), 2017.

Parker, R., Bösch, H., and Cogan, A.: Algorithm Theoretical Basis Document Version 2 (ATBDv2) The University of Leicester Full-Physics Retrieval Algorithm for the retrieval of $X_{\mathrm{CO}_{2}}$ and $X_{\mathrm{CH}_{4}}$, Tech. rep., University of Leicester, Leicester, UK, version 2, 2011.

Peters, W., Jacobson, A. R., Sweeney, C., Andrews, A. E., Conway, T. J., Masarie, K., Miller, J. B., Bruhwiler, L. M. P., Pétron, G., Hirsch, A. I., Worthy, D. E. J., van der Werf, G. R., Randerson, J. T., Wennberg, P. O., Krol, M. C., and Tans, P. P.: An atmospheric perspective on North American carbon dioxide exchange: CarbonTracker, P. Natl. Acad. Sci. USA, 104, 1892518930, https://doi.org/10.1073/pnas.0708986104, 2007.

Pougatchev, N., August, T., Calbet, X., Hultberg, T., Oduleye, O., Schlüssel, P., Stiller, B., Germain, K. St., and Bingham, G.: IASI temperature and water vapor retrievals - error assessment and validation, Atmos. Chem. Phys., 9, 6453-6458, https://doi.org/10.5194/acp-9-6453-2009, 2009.

Rayner, P. J. and O'Brien, D. M.: The utility of remotely sensed $\mathrm{CO}_{2}$ concentration data in surface source inversions, Geophys. Res. Lett., 28, 175-178, https://doi.org/10.1029/2000GL011912, 2001.

Reuter, M., Bovensmann, H., Buchwitz, M., Burrows, J. P., Heymann, J., and Schneising, O.: Algorithm Theoretical Basis Document Version 5 (ATBDv5) - The Bremen Optimal Estimation DOAS (BESD) algorithm for the retrieval of $X_{\mathrm{CO}_{2}}$, Tech. rep., Institute of Environmental Physics (IUP) University of Bremen, Bremen, Germany, version 5, 2016.

Reuter, M., Buchwitz, M., Schneising, O., Noël, S., Bovensmann, H., and Burrows, J. P.: A fast atmospheric trace gas retrieval for hyperspectral instruments approximating multiple scattering - Part 2: Application to $X_{\mathrm{CO}_{2}}$ retrievals from OCO-2, Remote Sensing, 9, 1102, https://doi.org/10.3390/rs9111102, 2017.

Rienecker, M. M., Suarez, M. J., Todling, R., Bacmeister, J., Takacs, L., Liu, H.-C., Gu, W., Sienkiewicz, M., Koster, R. D., Gelaro, R., Stajner, I., and Nielsen, J. E.: The GEOS-5 Data Assimilation System-Documentation of Versions 5.0.1, 5.1.0, and 5.2.0, Tech. rep., NASA Goddard Space Flight Center, Greenbelt, MD, available at: https://ntrs.nasa.gov/archive/nasa/casi. ntrs.nasa.gov/20120011955.pdf (last access: 27 February 2019), 2008.

Rienecker, M. M., Suarez, M. J., Gelaro, R., Todling, R., Bacmeister, J., Liu, E., Bosilovich, M. G., Schubert, S. D., Takacs, L., Kim, G.-K., Bloom, S., Chen, J., Collins, D., Conaty, A., da Silva, A., Gu, W., Joiner, J., Koster, R. D., Lucchesi, R., Molod, A., Owens, T., Pawson, S., Pegion, P., Redder, C. R., Reichle, R., Robertson, F. R., Ruddick, A. G., Sienkiewicz, M., and Woollen, J.: MERRA: NASA's modern-era retrospective analysis for research and applications, J. Climate, 24, 3624-3648, https://doi.org/10.1175/JCLI-D-11-00015.1, 2011.
Rödenbeck, C.: Estimating $\mathrm{CO}_{2}$ sources and sinks from atmospheric mixing ratio measurements using a global inversion of atmospheric transport, Tech. Rep. 6, Max Planck Institue für Biogeochemie, Jena, Germany, technical Report 6, 2005.

Rodgers, C. D.: Inverse Methods for Atmospheric Sounding: Theory and Practice, World Scientific, Singapore, 2000.

Schuh, A., Jacobson, A. R., Basu, S., Weir, B., Baker, D., Bowman, K., Chevallier, F., Crowell, S., Davis, K., Deng, F., Denning, S., Feng, L., Jones, D., Liu, J., and Palmer, P.: Quantifying the Impact of Atmospheric Transport Uncertainty on $\mathrm{CO}_{2}$ Surface Flux Estimates, Global Biogeochem. Cy., in review, 2019.

Stocker, T. F., Qin, D., Plattner, G.-K., Tignor, M., Allen, S., Boschung, J., Nauels, A., Xia, Y., Bex, V., and Midgley, P.: IPCC, 2013: Climate Change 2013: The Physical Science Basis. Contribution of Working Group I to the Fifth Assessment Report of the Intergovernmental Panel on Climate Change, Cambridge University Press, https://doi.org/10.1017/CBO9781107415324, 2014.

Susskind, J., Barnet, C. D., and Blaisdell, J. M.: Retrieval of atmospheric and surface parameters from AIRS/AMSU/HSB data in the presence of clouds, IEEE T. Geosci. Remote, 41, 390-409, https://doi.org/10.1109/TGRS.2002.808236, 2003.

Sussmann, R. and Rettinger, M.: TCCON data from Garmisch (DE), Release GGG2014.R0, TCCON Data Archive, hosted by CaltechDATA, https://doi.org/10.14291/tccon.ggg2014.garmisch01.R0/1149299, 2014.

Taylor, T. E., O’Dell, C. W., Frankenberg, C., Partain, P. T., Cronk, H. Q., Savtchenko, A., Nelson, R. R., Rosenthal, E. J., Chang, A. Y., Fisher, B., Osterman, G. B., Pollock, R. H., Crisp, D., Eldering, A., and Gunson, M. R.: Orbiting Carbon Observatory-2 (OCO-2) cloud screening algorithms: validation against collocated MODIS and CALIOP data, Atmos. Meas. Tech., 9, 973989, https://doi.org/10.5194/amt-9-973-2016, 2016.

Te, Y., Jeseck, P., and Janssen, C.: TCCON data from Paris (FR), Release GGG2014.R0, TCCON Data Archive, hosted by CaltechDATA, https://doi.org/10.14291/tccon.ggg2014.paris01.R0/1149279, 2014.

Warneke, T., Messerschmidt, J., Notholt, J., Weinzierl, C., Deutscher, N. M., Petri, C., Grupe, P., Vuillemin, C., Truong, F., Schmidt, M., Ramonet, M., and Parmentier, E.: TCCON data from Orléans (FR), Release GGG2014.R0, TCCON Data Archive, hosted by CaltechDATA https://doi.org/10.14291/tccon.ggg2014.orleans01.R0/1149276, 2014.

Wennberg, P. O., Roehl, C., Wunch, D., Toon, G. C., Blavier, J.-F., Washenfelder, R., Keppel-Aleks, G., Allen, N., and Ayers, J.: TCCON data from Park Falls (US), Release GGG2014.R0, TCCON Data Archive, hosted by CaltechDATA, https://doi.org/10.14291/tccon.ggg2014.parkfalls01.R0/1149161, 2014.

Wennberg, P. O., Wunch, D., Roehl, C., Blavier, J.-F., Toon, G. C., and Allen, N.: TCCON data from Caltech (US), Release GGG2014.R1, TCCON Data Archive, hosted by CaltechDATA, https://doi.org/10.14291/tccon.ggg2014.pasadena01.R1/1182415, 2015.

Wennberg, P. O., Wunch, D., Roehl, C., Blavier, J.-F., Toon, G. C., and Allen, N.: TCCON data from Lamont (US), Release GGG2014.R1, TCCON Data Archive, hosted by CaltechDATA, 
https://doi.org/10.14291/tccon.ggg2014.lamont01.R1/1255070, 2016.

Wunch, D., Toon, G. C., Blavier, J.-F. L., Washenfelder, R. A., Notholt, J., Connor, B. J., Griffith, D. W. T., Sherlock, V., and Wennberg, P. O.: The Total Carbon Column Observing Network, Philos. T. Roy. Soc. A, 369, 2087-2112, https://doi.org/10.1098/rsta.2010.0240, 2011.
Yang, D., Liu, Y., Cai, Z., Chen, X., Yao, L., and Lu, D.: First Global Carbon Dioxide Maps Produced from TanSat Measurements, Adv. Atmos. Sci., 35, 621-623, https://doi.org/10.1007/s00376018-7312-6, 2018.

Yokota, T., Yoshida, Y., Eguchi, N., Ota, Y., Tanaka, T., Watanabe, H., and Maksyutov, S.: Global Concentrations of $\mathrm{CO}_{2}$ and $\mathrm{CH}_{4}$ Retrieved from GOSAT: First Preliminary Results, Scientific Online Letters on the Atmosphere, 5, 160-163, https://doi.org/10.2151/sola.2009-041, 2009. 